\title{
Connexons and pannexons: newcomers in neurophysiology
}

\author{
Giselle Cheung, Oana Chever ${ }^{\dagger}$ and Nathalie Rouach* \\ Neuroglial Interactions in Cerebral Physiopathology, Center for Interdisciplinary Research in Biology, Collège de France, CNRS UMR 7241, INSERM U1050, \\ Labex Memolife, PSL Research University, Paris, France
}

\author{
Edited by: \\ Juan Andrés Orellana, Pontificia \\ Universidad Católica de Chile, Chile \\ Reviewed by: \\ Luc Leybaert, Ghent University, \\ Belgium \\ Mauricio Antonio Retamal, \\ Universidad del Desarrollo, Chile \\ *Correspondence: \\ Nathalie Rouach, Neuroglial \\ Interactions in Cerebral \\ Physiopathology, Center for \\ Interdisciplinary Research in Biology, \\ Collège de France, CNRS UMR \\ 7241, INSERM U1050, 11 Place \\ Marcelin Berthelot, Paris 75005, \\ France \\ e-mail:nathalie.rouach@ \\ college-de-france.fr \\ ${ }^{\dagger}$ Present address: \\ Oana Chever, Institute of Molecular \\ and Cellular Pharmacology, CNRS \\ UMR 7275 and University of \\ Nice-Sophia Antipolis, Valbonne, \\ France
}

Connexin hemichannels are single membrane channels which have been traditionally thought to work in pairs to form gap junction channels across two opposing cells. In astrocytes, gap junction channels allow direct intercellular communication and greatly facilitate the transmission of signals. Recently, there has been growing evidence demonstrating that connexin hemichannels, as well as pannexin channels, on their own are open in various conditions. They allow bidirectional flow of ions and signaling molecules and act as release sites for transmitters like ATP and glutamate into the extracellular space. While much attention has focused on the function of connexin hemichannels and pannexons during pathological situations like epilepsy, inflammation, neurodegeneration or ischemia, their potential roles in physiology is often ignored. In order to fully understand the dynamic properties and roles of connexin hemichannels and pannexons in the brain, it is essential to decipher whether they also have some physiological functions and contribute to normal cerebral processes. Here, we present recent studies in the CNS suggesting emerging physiological functions of connexin hemichannels and pannexons in normal neuronal activity and behavior. We also discuss how these pioneer studies pave the way for future research to extend the physiological relevance of connexons and pannexons, and some fundamental issues yet to be addressed.

Keywords: neurons, astrocytes, synapses, plasticity, learning and memory, connexins, pannexins, hemichannels

\section{INTRODUCTION}

A typical feature of glia, in particular astrocytes, is to express high levels of connexins (Cxs), which have long been thought to only provide the molecular basis for the formation of gap junction (GJ) channels, mediating the extensive direct glial intercellular communication (Spray et al., 1999; Rozental et al., 2000; Theis et al., 2005; Pannasch and Rouach, 2013). Indeed Cxs, which represent a family of so far $\sim 20$ isoforms identified in mice and humans (Willecke et al., 2002), form homomeric or heteromeric hexamers on cell plasma membranes. These structures also called connexons, can align and dock with other connexons provided by neighboring cells to form GJ channels (Sáez et al., 2003). Such GJ channels thus connect the cytoplasm of adjacent cells. They allow direct exchange of a variety of small molecules $<1.5 \mathrm{kDa}$ (Loewenstein, 1981), including ions, energy metabolites, neurotransmitters and signaling molecules, coordinating electrical and metabolic activities of connected cells (Dermietzel and Spray, 1993; Pannasch and Rouach, 2013). Importantly, GJ functions have been attributed to various CNS pathologies as both protective and destructive (Rouach et al., 2002; Eugenin et al., 2012). However, over the last years, increasing evidence has emerged showing that astrocytic gap-junctional networks can also modulate physiological activities like synaptic transmission, plasticity and information processing (Lutz et al.,
2009; Pannasch et al., 2011; Pannasch and Rouach, 2013; Han et al., 2014).

Nevertheless, besides the classical formation of GJ channels, connexons do exist on their own as single membrane channels, named hemichannels (HCs), which directly connect the cell cytoplasm to the extracellular space. Because HCs are thought to be poorly selective large pore channels permeable to numerous low molecular weight molecules, their opening is commonly viewed as deleterious due to potential loss of cytoplasmic integrity and neurotoxic damage that may be induced by the released factors (Giaume et al., 2013). Such membrane HCs were thus at first presumed to be closed and to serve as a reserve pool of connexons ready to be assembled into GJ channels at junctional plaques. However, this concept has been challenged in the nineties, when Cx HCs were for the first time reported to open in a number of conditions, albeit mostly related to pathological situations, as recently reviewed (Orellana et al., 2012b, 2013; Giaume et al., 2013).

Remarkably another family of proteins, the pannexins (Panxs), was discovered in the early 2000s to be homologous to the invertebrate GJ forming proteins innexins (Baranova et al., 2004). Although Panxs were initially suspected to form GJ channels due to their structural similarities to Cxs, thus far they have actually been shown in native systems to only form large pore membrane 
channels, similar to Cx HCs. Differential expression and properties of Cx HCs and Panx subtypes in glial cells (Cx43 and Panx1 in astrocytes; Cx43, Cx32, and Panx1 in microglia; Panx1 and possibly Cx29 or Cx32 in oligodendrocytes) and neurons (Cx36 and Panx1) have already been summarized in several comprehensive reviews (Sáez et al., 2003; Thompson and Macvicar, 2008; Orellana et al., 2011c; Giaume et al., 2013). In addition, like Cx HCs, the activation of Panx channels is generally also viewed as detrimental and has accordingly been mostly reported during pathological conditions, as recently extensively reviewed (Bennett et al., 2012; Giaume et al., 2013; Mylvaganam et al., 2014; Orellana et al., 2014; Velasquez and Eugenin, 2014). Interestingly, with these growing findings on HCs properties and roles inside and outside the brain, it was hypothesized that these channels may also have their importance in physiology. Indeed, a few pioneer studies have shown that HCs do open in physiological conditions in the retina (Pearson et al., 2005) or in the inner ear (Anselmi et al., 2008). This has led to the emergence of several recent studies over the last few years focusing on their physiological functions. In particular, $\mathrm{Cx} 43 \mathrm{HCs}$, and Panx1 channels, among others, have been most commonly investigated in various physiological contexts. Although not much is known about $\mathrm{Cx}$ and Panx single membrane channels in the brain during physiological conditions and if they could modulate synaptic transmission and behavior, a few recent studies have explored this possibility. Here, we review these findings on connexons and pannexons focusing on their novel neurophysiological and behavioral roles in the CNS, as well as the experimental approaches used. In addition, future directions and prospects in unraveling the physiological relevance of these channels are also discussed.

\section{UNIQUE FEATURES OF CONNEXINS AND PANNEXINS AS SINGLE MEMBRANE CHANNELS}

Cx HCs and Panx channels are unique membrane channels due to their large pores with specific conductance properties (Thompson and Macvicar, 2008). This type of channels potentially represents a more dynamic aspect of such transmembrane pores, as their opening to the extracellular space may promote direct regulation of neurotransmission and paracrine signaling. While functions of Cx GJ channels have been extensively investigated and characterized, the properties of Cxs and Panxs as unapposed single membrane channels, or HCs, have only recently been given attention and explored. Over the last years, different experimental approaches have been developed to investigate the properties of HCs. As summarized in Table 1, these include the use of tracers permeable to HCs, quantification of released molecules and electrophysiological recordings of $\mathrm{HC}$ currents. Moreover, HC activities can also be manipulated by the addition of mimetic peptides, pharmacological blockers, antibodies or various transgenic animals. These techniques have greatly contributed to the identification of many unique features of $\mathrm{Cx}$ HCs and Panx channels.

\section{CONNEXIN HEMICHANNELS}

The first studies to show evidence for functional HCs was on rat lens fiber Cx46 expressed in xenopus oocytes (Paul et al., 1991; Ebihara and Steiner, 1993). In particular, the authors have identified non-junctional voltage dependent currents in Cx46 expressing oocytes, which they have later confirmed in lens fiber (Ebihara et al., 2011). Functional Cx30, Cx46 and Cx50 HCs have also been detected using HeLa cell expression system, but were found to be closed during physiological conditions (Valiunas and Weingart, 2000). Indeed, extracellular binding of $\mathrm{Ca}^{2+}$, intracellular phosphorylation and strong voltagedependence are hindering the opening of $\mathrm{Cx}$ HCs near resting membrane potentials. More subsequent studies have observed similar HC properties of Cx30.2 and Cx31.9 (Bukauskas et al., 2006), Cx43 (Contreras et al., 2003; Kang et al., 2008), and Cx26 (Gonzalez et al., 2006), although human Cx26 HCs have been shown in the inner ear to open in physiological conditions, where they sustain long range intercellular $\mathrm{Ca}^{2+}$ signals (Anselmi et al., 2008). Noteworthy, a physiologically low $\mathrm{Ca}^{2+}$ level inside cochlear endolymph (Bosher and Warren, 1978) is likely the reason why Cx26 HCs are open and participate in physiological signaling in the inner ear. Remarkably, HCs properties differ according to the $\mathrm{Cx}$ composition, which confers distinctive permeability and biophysical properties, including open probability, conductance and selectivity (Giaume et al., 2013). In addition, Cx HCs are strongly regulated, and some triggers for their opening include transmembrane voltage, changes in $\mathrm{Ca}^{2+}$ and $\mathrm{K}^{+}$concentrations, ATP or post-transcriptional modifications of the channels, which have been extensively reviewed (Sáez et al., 2005; Macvicar and Thompson, 2010; Giaume et al., 2013; Orellana et al., 2013; Wang et al., 2013a). Finally, these HCs provide a direct means for signaling molecules like ATP and glutamate to travel between intra- and extracellular space (Giaume et al., 2013). In particular, the release of extracellular messengers like ATP via Cx HCs are of significant importance and has been shown to contribute to astroglial $\mathrm{Ca}^{2+}$ waves (Leybaert and Sanderson, 2012). Since their discoveries, many other signaling molecules like $\mathrm{NAD}^{+}$, glutamate, glutathione and prostaglandin E2 have been found to be released via $\mathrm{Cx} \mathrm{HCs}$ (Wang et al., 2013a), suggesting multiple dynamic functions of Cx HCs.

\section{PANNEXIN CHANNELS}

In 2004, a new type of GJ proteins homologous to the invertebrate innexins family was cloned (Baranova et al., 2004). Three members of this family, the Pannexins (Panxs) have been identified, with Panx1 expressed ubiquitously, Panx2 specifically in the brain, and Panx3 in osteoblasts and synovial fibroblasts (Baranova et al., 2004). In addition, Panx1 are found to be more abundant during early neuronal development and Panx2 later (Penuela et al., 2007). Interestingly, with little sequence homology, the Panxs share very similar topology and structure with the Cxs, displaying four transmembrane domains, two extracellular- and one intracellular- loop, as well as intracellular N- and C-termini (D'hondt et al., 2009). However, in contrast to Cxs, Panxs normally act in native systems as single membrane large pore channels rather than GJs (Penuela et al., 2007; Sosinsky et al., 2011). In fact, the only evidence of Panx GJ formation was demonstrated in overexpression systems in specific cell lines and showed distinct properties from Cx GJ channels (Bruzzone et al., 2003; Lai et al., 2007; Sahu et al., 2014). 


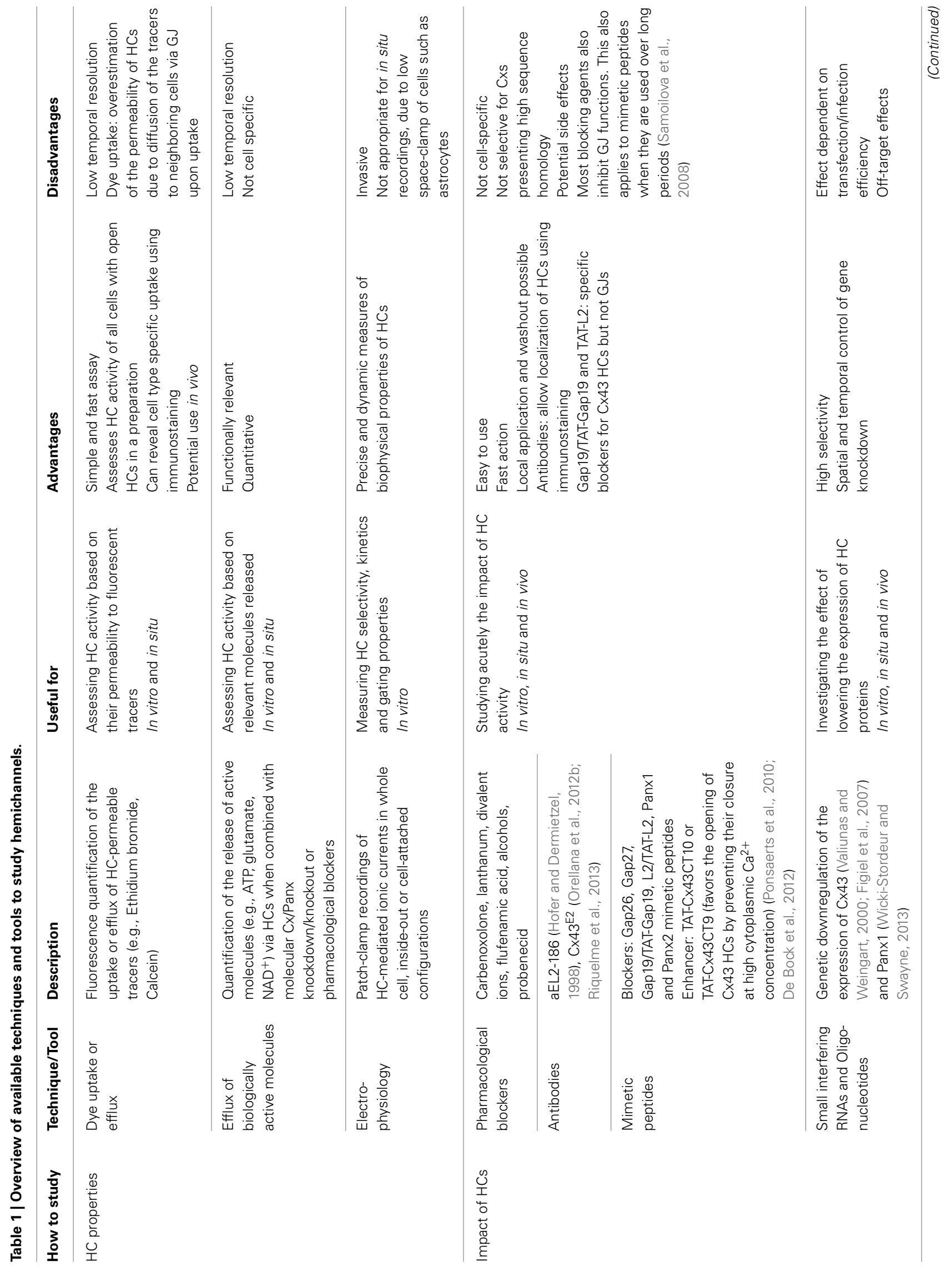




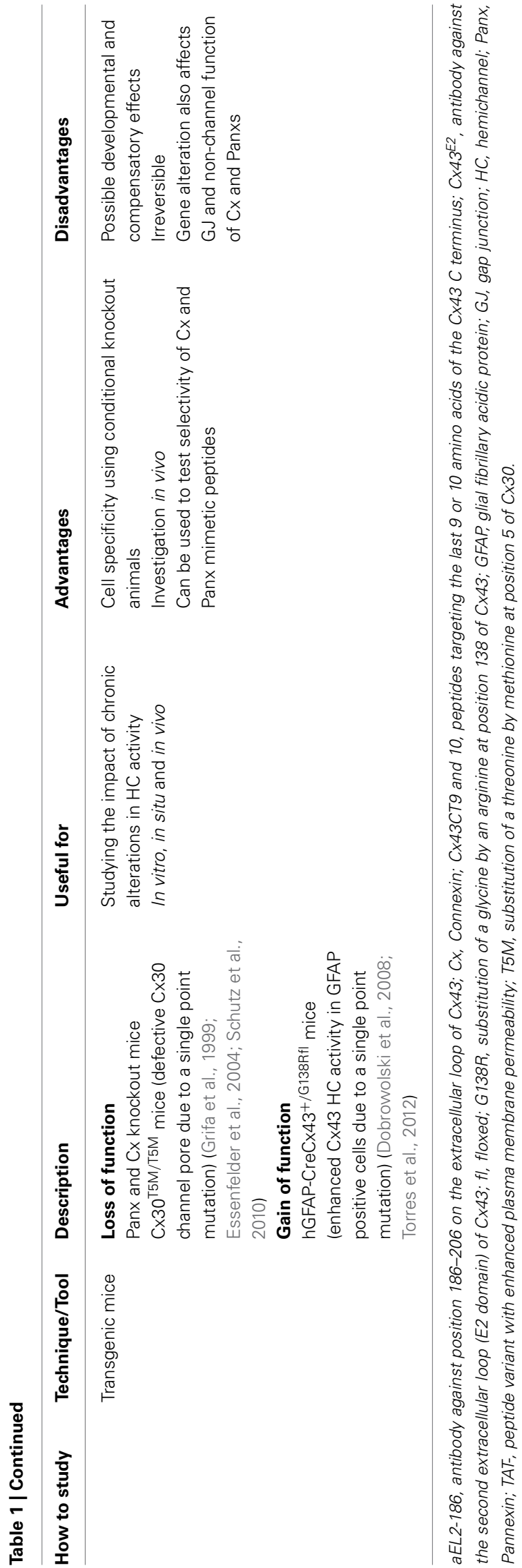

Moreover, like Cx HCs, Panx channels can release numerous signaling molecules such as ATP or glutamate (Ye et al., 2003; Iglesias et al., 2009; Giaume et al., 2013). Remarkably, a unique property of Panxs is that they are glycosylated extracellularly at an arginine residue (Boassa et al., 2008). This glycosylation process has been proposed to be the limiting factor preventing Panx channels on adjacent cells from forming GJ channels. Thus, rare gap-junctional formation was only observed when Panx1 was overexpressed to a level exceeding glycosylation capacity (Bruzzone et al., 2003; Lai et al., 2007; Sahu et al., 2014). Concerning the biophysical properties of Panx channels, they are still elusive and controversial, most likely due to the recent discovery of Panxs compared to Cx HCs. Indeed, for instance unitary conductance of Panx1 channels has been reported to range from $\sim 70$ to $550 \mathrm{pS}$, which may reflect different recording conditions, cell type properties or sub-conductance states (Locovei et al., 2006; Kienitz et al., 2011; Ma et al., 2012). While the expression of Panx1 overlaps with that of Cxs mediating extensive GJ coupling in cellular networks (Ray et al., 2005), it was found to be distinctively regulated as compared to the Cxs (Penuela et al., 2007), implying unique functional significance of Panx channels. For instance, while many reports have demonstrated sensitivity of $\mathrm{Cx} \mathrm{HCs}$ to extracellular $\mathrm{Ca}^{2+}\left(\left[\mathrm{Ca}^{2+}\right]_{e}\right)$, which is commonly thought to keep HCs in a closed state at physiological $\left[\mathrm{Ca}^{2+}\right]_{\mathrm{e}}$ (Ebihara et al., 2003), Panxs appear to be insensitive to this (Bruzzone et al., 2005). In addition, Panx1 channels do not show the strong voltage-dependence typical of $\mathrm{Cx} \mathrm{HCs}$ (Bruzzone et al., 2003). Thus, this type of insensitivity suggests that Panx channel activity does not depend on neuronal activity and that Panx channels might be open during basal physiological conditions.

\section{EMERGING ROLES OF CONNEXON AND PANNEXON CHANNELS IN NEUROPHYSIOLOGY AND BEHAVIOR}

Cx HCs and Panxs as single membrane channels have undoubtedly many roles in CNS pathologies involving inflammation (Orellana et al., 2011a; Bennett et al., 2012; Makarenkova and Shestopalov, 2014), ischemia (Contreras et al., 2004; Bargiotas et al., 2011), epilepsy (Thompson et al., 2008) and neurodegeneration (Orellana et al., 2011b, 2012b). For a long time, it was believed that $\mathrm{Cx}$ HCs and Panx channels with large channel conductance would remain closed in normal conditions in order to maintain cellular integrity and to prevent unregulated transmitter release into the extracellular space. It is indeed conceivable that, like many membrane channels, these Cx HCs and Panxs serve as a direct and effective way to relieve cells from any homeostatic imbalances found in many pathological situations (Bennett et al., 2012; Giaume et al., 2013). Given that specific HCs are found to be active outside the brain in physiological settings (Anselmi et al., 2008), and that Panx channels have unique properties favoring channel opening under the same conditions, a few pioneer groups began to postulate that these channels might also have some relevance in basal neuronal processes. Here, we review the few recent studies examining roles of $\mathrm{Cx}$ and Panx single membranes large pore channels on physiological functions ranging from cell division to learning and memory. 


\section{DEVELOPMENT}

During CNS development including embryonic and adult neurogenesis, purinergic signaling is believed to have crucial contributions (Zimmermann, 2011). Indeed, ATP receptor activation was found to play a role in proliferation and DNA synthesis in astrocytes (Neary and Zhu, 1994) and neural stem cells (Ryu et al., 2003). The fact that both Cx43 HCs and Panxl channels are permeable to ATP makes them candidates for purinergic signaling during development. The involvement of Cx43 HCs in these fundamental cellular processes was first explored in embryonic retina. As a result, they were found to play a role in cell division and proliferation (Pearson et al., 2005). The authors have demonstrated that upon spontaneous $\mathrm{Ca}^{2+}$ increase in a "trigger cell" in the retinal pigment epithelium, ATP is released via Cx43 HCs into the extracellular space adjacent to retinal progenitor cells during development, promoting mitosis and proliferation. In addition, the released ATP also triggers the spread of $\mathrm{Ca}^{2+}$ waves through neighboring retinal pigment epithelial cells. Both of these mechanisms involve $\mathrm{P} 2$ receptor activation. A short application (30 min) of the mimetic peptide Gap26, which specifically blocks $\mathrm{Cx} 43 \mathrm{HCs}$ without affecting GJ functions, was used to test the involvement of $\mathrm{Cx} 43 \mathrm{HCs}$, whereas $\mathrm{HC}$ activity in retinal pigment epithelial cells was measured by Alexa 488 dye efflux assay. In a more recent study, functional Panx1 channels were identified in postnatal neural stem and progenitor cells both in vitro and in vivo (Wicki-Stordeur et al., 2012). Panx1 channel specific effect was investigated using Panxl siRNA knockdown in vitro and/or probenecid, a blocker of Panxl channels without affecting $\mathrm{Cx}$ HCs. These results were found to positively regulate proliferation of these cell types via ATP release and subsequent P2 receptor activation. The same group later demonstrated that Panx1 also plays a role in cell migration and neurite extension through its interaction with actin cytoskeleton (Wicki-Stordeur and Swayne, 2013). These results are interesting, since adult neurogenesis plays important roles in both physiological brain development as well as brain repair during pathology and diseases (Berg et al., 2013). Although astrocytic Cx43 and Cx30 have been shown to differentially regulate adult neurogenesis in knockout mice (Liebmann et al., 2013), it was not clear whether it was via their GJ or HC properties. The potential involvement of $\mathrm{Cx} 43 \mathrm{HCs}$ in embryonic retinal development and Panx 1 channels in adult neurogenesis is encouraging and may offer important insights into other possible non-synaptic physiological functions of single membrane channels yet to be discovered.

\section{GLUCOSE SENSING AND SIGNAL TRANSDUCTION}

Apart from promoting cell division and proliferation, the activities of $\mathrm{Cx} 43 \mathrm{HCs}$ and Panx1 channels have also recently been proposed to be modulated by changes in extracellular glucose concentrations. Neuronal glucose-sensing is an important physiological process in the hypothalamus, in which action potentials are driven by changes in extracellular glucose concentration. This has been shown to largely contribute to feeding and satiety behavior, sleep-wake cycles, and energy expenditure (Levin et al., 2004; Burdakov et al., 2005). In astrocytes, glucose uptake via Cx43 HCs has already been demonstrated under inflammatory conditions (Retamal et al., 2007). However, whether this is also true in physiology remains unclear. Recently, the role of glial Cx43 HCs in glucose-sensing was explored using cultured tanycytes, which are specialized glial cells in the hypothalamus (Orellana et al., 2012a). The authors showed that, upon a rise in extracellular glucose concentration, glucose transporters (GLUTs) and to a lesser extent Cx43 HCs, allow diffusion of glucose into tanycytes, where it leads to increase in ATP. Subsequently, ATP is released via Cx43 HCs, which then stimulates $\mathrm{P} 2 \mathrm{Y}$ receptors locally leading to the rise of $\left[\mathrm{Ca}^{2+}\right]_{i}$. Both ATP release and $\left[\mathrm{Ca}^{2+}\right]_{i}$ responses were inhibited by $\mathrm{Cx} 43 \mathrm{HC}$ blocking agents like $\mathrm{La}^{3+}$, Gap26, and $\mathrm{Cx} 43^{\mathrm{E} 2}$ (an antibody against the second extracellular loop of $\mathrm{Cx} 43$ ). The opening of $\mathrm{Cx} 43 \mathrm{HCs}$ was found to be promoted by the closing of $\mathrm{K}_{\mathrm{ATP}}$ channels. Interestingly, this serie of events does not require extracellular $\mathrm{Ca}^{2+}$. Using ethidium bromide uptake assay, electrophysiology, and surface biotinylation, they have demonstrated that the open probability of $\mathrm{Cx} 43 \mathrm{HCs}$, rather than their number, was enhanced by glucose. Although it was recently demonstrated that $\mathrm{Cx} 30$ but not $\mathrm{Cx} 43$ HCs expressed on oocytes are permeable to glucose (Hansen et al., 2014), these results have revealed a new role of $\mathrm{Cx} 43 \mathrm{HCs}$ in physiological situation, namely to sense and metabolize extracellular glucose. Further studies on how this directly affects glucose metabolism in the hypothalamus, as well as behavioral modifications in vivo would largely complement these data and draw physiological relevance. Since tanycytes express a majority of $\mathrm{Cx} 43$ rather than Panxs, it is not surprising that Panxs were found not to be involved in this process. However, it would be interesting to explore whether astrocytic Panxs participate in similar signaling pathways. In fact, the involvement of Panxs in metabolic autocrine regulation has been previously demonstrated (Kawamura et al., 2010). The authors showed that non-pathological changes in extracellular glucose concentration induce a purinergic autoregulation in hippocampal CA3 neurons. This was found to be mediated by the opening of Panx1 channels on neurons, but not astrocytes. Although this study was designed to determine the effect of the anti-epileptic ketogenic diet (high fat and low carbohydrates) on increasing seizure threshold, it gave important insights into how Panxl channels could be involved in regulating physiological metabolic perturbations.

\section{NEURONAL EXCITABILITY AND SYNAPTIC TRANSMISSION}

Astrocytes express a large repertoire of ions channels, neurotransmitter receptors and transporters, allowing them to sense and modulate neuronal activity through multiple mechanisms. These include in part intracellular calcium signaling, morphological changes or gliotransmission, in which neuroactive substances such as glutamate or ATP are released from astrocytes and act on neurons. The opening of Cx HCs and Panx channels during physiological conditions suggests that they represent a release pathway of gliotransmitters and ions, which can regulate neuronal excitability and basal synaptic transmission. Here, we first present findings related to ATP release via astroglial Cx43 HCs and synaptic transmission. In particular, among several recent studies demonstrating physiological relevance of $\mathrm{Cx} 43$ $\mathrm{HCs}$, we have very recently shown that astroglial $\mathrm{Cx} 43 \mathrm{HCs}$ are not only open in acute hippocampal slices under physiological conditions, but can also modulate basal excitatory synaptic transmission through ATP signaling (Chever et al., 2014). 
Specifically, we reported that ethidium bromide uptake into astrocytes under basal conditions was decreased in the presence of the HC blocker carbenoxolone (CBX) or the $\mathrm{Cx} 43 \mathrm{HC}$ mimetic blocking peptide Gap26. These blocking agents had no effect on ethidium bromide uptake in brain slices prepared from $\mathrm{Cx} 43^{\mathrm{fl} / \mathrm{fl}}$ hGFAP-Cre mice $\left(\mathrm{Cx} 43^{-/-}\right)$. These strongly suggested that functional astroglial $\mathrm{Cx} 43 \mathrm{HCs}$ are present under physiological conditions (Figures 1A,B). Interestingly, excitatory postsynaptic currents recorded in CA1 pyramidal neurons and ATP release from hippocampal slices detected using a luciferinluciferase luminescence assay were also concurrently decreased in the presence of Gap26. Furthermore, pretreatment with ATP $\mathrm{P} 2 \mathrm{X}$ and $\mathrm{P} 2 \mathrm{Y}$ receptor antagonists abolished the inhibitory effect of Gap26 on excitatory synaptic activity, suggesting the involvement of $\mathrm{P} 2$ receptors (Figure 1C). Our results thus suggest a novel physiological pathway involving functional astroglial Cx43 HCs and ATP release in tuning excitatory synaptic transmission in the hippocampus.

The involvement of HCs in promoting astrocytic $\mathrm{Ca}^{2+}$ waves by ATP release (Cotrina et al., 1998) suggested another possible means for HCs to contribute to physiological cell-cell interaction and propagation of signals. In fact, this has already been demonstrated in the inner ear. Both $\mathrm{Cx} 26$ and $\mathrm{Cx} 30$ were found to play a role in propagating long-range intercellular $\mathrm{Ca}^{2+}$ signaling in cochlear organotypic cultures (Anselmi et al., 2008). These Cxs contributed by HC-mediated ATP release as well as gap-junctional diffusion of $\mathrm{Ca}^{2+}$-mobilizing second messengers. A recent study (Torres et al., 2012) has taken a different approach to study $\mathrm{HC}$ function by directly decreasing $\left[\mathrm{Ca}^{2+}\right]_{\mathrm{e}}$ (by $0.5 \mathrm{mM}$ ), to a range thought to occur during neuronal network activity
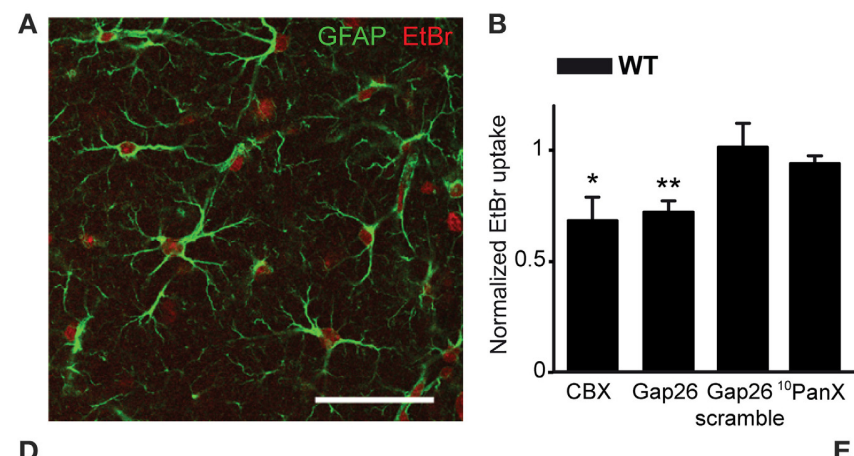

D

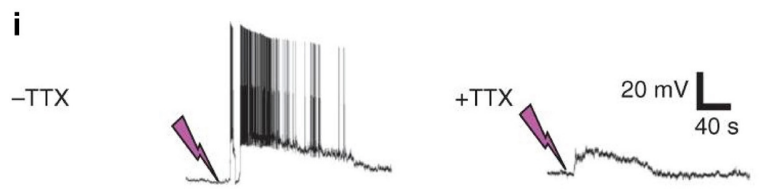

ii

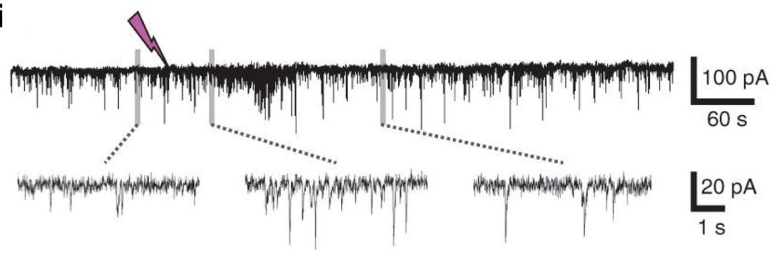

FIGURE 1 | Astrocytic Cx43 HCs modulate synaptic transmission in hippocampal slices. (A-C) Basal astroglial $\mathrm{C} \times 43 \mathrm{HC}$ activity enhances excitatory synaptic transmission via ATP signaling. (A) Representative image showing ethidium bromide uptake $(\mathrm{EtBr}$; red) in astrocytes (immunostained for GFAP; green) of the stratum radiatum in an acute hippocampal slice. Scale bar, $50 \mu \mathrm{m}$. (B) Bar graphs showing astrocytic EtBr uptake in brain slices obtained from wild-type (WT) and astroglial conditional $\mathrm{C} \times 43 \mathrm{KO}\left(\mathrm{C} \times 43^{-1-}\right)$ mice normalized to control (untreated) conditions. Uptake was significantly deceased in WT slices treated with carbenoxolone (CBX, $200 \mu \mathrm{M})$ and Gap26 $(100 \mu \mathrm{M})$, but not Gap26 scramble $(100 \mu \mathrm{M})$ and ${ }^{10}$ panx $(400 \mu \mathrm{M})$ peptides. In Cx43-1- slices, however, both CBX and Gap26 had no significant effect. (C) Bar graph on the left showing a decrease in amplitude of evoked EPSC recorded in CA1 pyramidal neurons during Gap26 application (red) as compared to before ( $\mathrm{Ct}$, black). Bar graph on the right showing that pretreatment with ATP P2 receptor antagonists (RB2 + PPADS, gray) occludes the effect of Gap26 (red). Sample traces of corresponding evoked EPSCs are shown above. Scale bar: 20 pA, $20 \mathrm{~ms}$ (left); 40 pA, $40 \mathrm{~ms}$ (right).
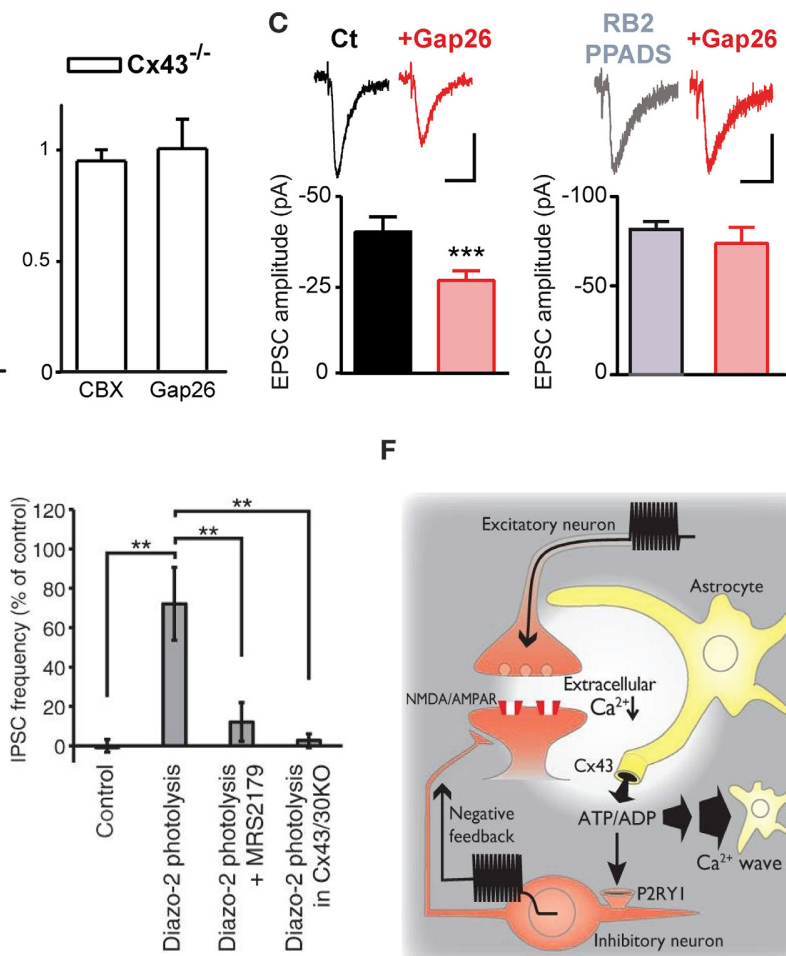

$\mathbf{F}$

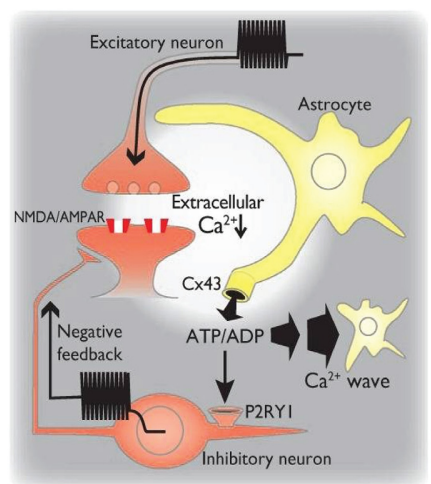

(D-F) Cx43 HCs in astrocytes promote feedback inhibitory transmission by releasing ATP. (D) Representative recordings showing that photolysis of diazo-2, represented by lightning bolts, (i) evokes depolarization and bursting in interneurons, with the depolarization persisting with $1 \mu \mathrm{M} \mathrm{TTX}$, and (ii) transiently increases the frequency of spontaneous inhibitory postsynaptic currents (IPSCS) in CA1 pyramidal neurons. (E) Bar graph indicating increased IPSC frequency in pyramidal neurons after diazo-2 photolysis compared to control condition. This effect was blocked by the P2Y1 receptor antagonist MRS2179 $(50 \mu \mathrm{M})$ or in brain slices prepared from Cx43/Cx30KO mice. (F) Schematic diagram illustrating a proposed negative feedback mechanism during excitatory transmission. During glutamatergic signaling, $\mathrm{Ca}^{2+}$ influx into neurons results in a localized decrease in $\left[\mathrm{Ca}^{2+}\right]_{e}$, which in turn opens Cx43 HCs on astrocytes through which ATP is released. ATP can either trigger slowly propagating astrocytic $\mathrm{Ca}^{2+}$ waves or, when degraded to ADP, depolarize and increase firing in interneurons via $\mathrm{P} 2 \mathrm{Y} 1$ receptors, thereby enhancing inhibitory transmission. ${ }^{*} p<0.05 ;{ }^{* *} p<0.01 ;{ }^{* * *} p<0.001$. Adapted, with permission, from Torres et al. (2012) (D-F). 
(Massimini and Amzica, 2001; Amzica et al., 2002). Since low $\left[\mathrm{Ca}^{2+}\right]_{e}$ has been found to open Cx HCs (Sáez et al., 2005), the effect of lowering $\left[\mathrm{Ca}^{2+}\right]_{\mathrm{e}}$ on synaptic transmission and the involvement of HCs in this process was investigated. Specifically, $\left[\mathrm{Ca}^{2+}\right]_{\mathrm{e}}$ in acute hippocampal slices was decreased using several methods including uncaging $\mathrm{Ca}^{2+}$ chelator (diazo2) or glutamate (MNI-glutamate) extracellularly. In an attempt to draw physiological relevance, high frequency stimulation-induced decrease in $\left[\mathrm{Ca}^{2+}\right]_{\mathrm{e}}$ was also assessed. With these manipulations to decrease $\left[\mathrm{Ca}^{2+}\right]_{e}$, they detected an increase in extracellular ATP concentration, which triggered a slow astrocytic $\mathrm{Ca}^{2+}$ wave. Such ATP release was proposed to be mediated by astroglial $\mathrm{Cx} 43 \mathrm{HCs}$, using a combination of molecular and pharmacological tools. $\mathrm{Cx} 30^{-/-} \mathrm{Cx} 43^{\mathrm{fl} / \mathrm{fl}}$ hGFAP-Cre mice, with conditional deletion of $\mathrm{Cx} 43$ in astrocytes and total deletion of Cx30 (Wallraff et al., 2006), were used to avoid compensatory up-regulation of $\mathrm{Cx} 30$ (Theis et al., 2003). Astroglial $\mathrm{Ca}^{2+}$ waves were abolished in these mice. In comparison, $\mathrm{C} \times 30^{-/-} \mathrm{Cx} 43^{\mathrm{fl} / \mathrm{fl}}$ mice $(\mathrm{Cx} 30 \mathrm{KO})$ were used to show that no alteration in astrocytic $\mathrm{Ca}^{2+}$ waves was observed with functional $\mathrm{Cx} 43$. In addition, transgenic mice with an astrocyte-targeted point mutation of $\mathrm{Cx} 43$ (glycine 138 substituted with arginine) were also used. In such mice, thought to display an increased number of open $\mathrm{Cx} 43 \mathrm{HCs}$, but also deficient gap junctional coupling (Dobrowolski et al., 2008), astroglial $\mathrm{Ca}^{2+}$ waves were enhanced. Finally, CBX, a pharmacological inhibitor of both Cx HCs and GJ channels was found to abolish the evoked astroglial slow $\mathrm{Ca}^{2+}$ waves. In these experiments, which exclude a contribution of $\mathrm{Cx} 30$ in the evoked astroglial slow $\mathrm{Ca}^{2+}$ waves, whether $\mathrm{Cx} 43 \mathrm{GJ}$ channels also contribute to astroglial $\mathrm{Ca}^{2+}$ signaling is still an open question. Interestingly, the authors also showed that ATP released by Cx43 HCs subsequently activated $\mathrm{P} 2 \mathrm{Y} 1$ receptors on inhibitory interneurons, which potentiated their excitability and thereby inhibitory synaptic transmission (Figures 1D,E). Thus, in response to intense neuronal activity where $\left[\mathrm{Ca}^{2+}\right]_{e}$ is significantly decreased, astrocytic $\mathrm{Cx} 43 \mathrm{HCs}$ were proposed to play a complex role in a negative feedback mechanism by initiating and propagating inhibition to tone down strong excitatory transmission and hypexcitability of neuronal networks (Figure 1F). This study suggests an interesting link between $\mathrm{HC}$-mediated astrocytic $\mathrm{Ca}^{2+}$ waves and inhibitory synaptic transmission in response to intense neuronal activity. However, it is not clear whether all the experimental protocols used in this study generated a decrease in $\left[\mathrm{Ca}^{2+}\right]_{\mathrm{e}}$ that is within a physiologically relevant range. Additional studies are therefore warranted to demonstrate that the regulation of neuronal activity by astroglial Cx43 HCs also applies to physiological conditions. In addition, it is unclear whether the decrease in $\left[\mathrm{Ca}^{2+}\right]_{\mathrm{e}}$ used in this study induces significant $\mathrm{Cx}$ HC opening in astrocytes. Indeed, although slight decrease in $\left[\mathrm{Ca}^{2+}\right]_{\mathrm{e}}$, from 1.8 to $1.6 \mathrm{mM}$, has been found to open Cx HCs in cell lines (Quist et al., 2000), in cultured astrocytes $\left[\mathrm{Ca}^{2+}\right]_{\mathrm{e}}$ below $1 \mathrm{mM}$ is necessary to significantly open HCs, as assessed by HCmediated glutamate release (Ye et al., 2003). Finally, it still remains unknown whether ATP activated P2Y1 receptors in other cells than interneurons, such as astrocytes, where they can contribute to glutamatergic gliotransmission (Jourdain et al., 2007; Pascual et al., 2012).
ATP-mediated modulations of neurotransmission are not only restricted to astroglial $\mathrm{Cx} 43$ HCs. Indeed, an interesting link between Panx channels, which also release ATP, and basal neuronal excitability was reported (Kawamura et al., 2010). Using whole-cell patch clamp recordings, it was demonstrated that changes in extracellular glucose concentration from 11 to $3 \mathrm{mM}$ opened Panx1 channels on rat hippocampal CA3 pyramidal neurons through which ATP is released. Its metabolite adenosine then activates adenosine $\mathrm{Al}$ receptors, leading to the opening of ATP-sensitive $\mathrm{K}^{+}$channels. As a result of this autocrine regulation, neuronal hyperpolarization occurs, downregulating neuronal activity. The involvement of Panxl channels was confirmed using $\mathrm{CBX}$, octanol and the selective peptide blocker ${ }^{10}$ panx (Figures 2A,B). Of note, although decreasing glucose concentration to $3 \mathrm{mM}$ was confirmed to be non-pathological using extracellular recordings, an initial concentration of $11 \mathrm{mM}$ is almost four-fold higher than extracellular glucose concentration in brain tissues in vivo (Shram et al., 1997). Whether this initial hyperglycemic condition contributed to the Panx1-mediated regulation of neuronal activity thus remains to be clarified.

Following this report, two other studies have demonstrated using Panx $1^{-/-}$mice and/or pharmacological blockade of Panx1 channels that Panx1 also plays an important role in synaptic transmission. Prochnow and colleagues observed a significant increase in synaptic transmission in adult $\mathrm{Panx}^{-/-}$mice by measuring the input-output curves at the hippocampal Schaffercollateral CA1 synapse (Prochnow et al., 2012). Interestingly, this effect was abolished in the presence of adenosine, suggesting that involvement of ATP release via Panx1 channels might be involved (Figure 2C). Similar experiments were later performed by another group (Ardiles et al., 2014). Importantly, this later study showed that the enhanced synaptic transmission in Panx $1^{-/-}$mice was only observed in adult (9-12 month-old) but not in young ( 1 month-old) mice. They also saw a similar enhancement in synaptic transmission by treating adult brain slices with a Panx1 channel blocker, probenecid, further confirming their observations. This effect was not related to change in presynaptic release probability, as assessed by paired pulse facilitation. The authors however postulated that Panx1 deletion could reduce ATP release and thus extracellular adenosine levels, leading to an increase in glutamate release, as previously proposed (Prochnow et al., 2012). To indirectly support this hypothesis, they experimentally increased synaptic glutamate levels using a glutamate transporter blocker (TBOA), and observed a larger increase in fEPSP in adult Panx1 $1^{-/-}$and probenecid-treated control than in untreated control. However, direct evidence of pre- and/or postsynaptic effects is still lacking. It would also be interesting to determine whether the effects observed are mediated by neuronal and/or glial Panx1 channels.

\section{SYNAPTIC PLASTICITY, LEARNING, AND MEMORY}

With these growing reports suggesting important roles of $\mathrm{Cx} \mathrm{HCs}$ and Panx channels in neuronal excitability and synaptic transmission, some groups became interested in studying their functional significance in terms of synaptic plasticity as well as learning and memory. It is indeed believed that astrocytes have many essential roles in synaptic functions, including synaptic plasticity 

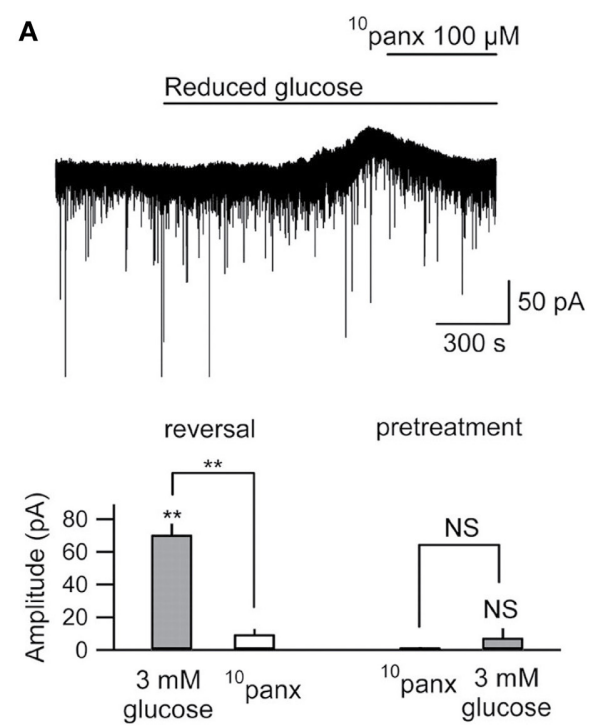

C -0 - $-(n=18)$ $\cdots+1+(n=16)$ - - - Adenosine $(n=7)$

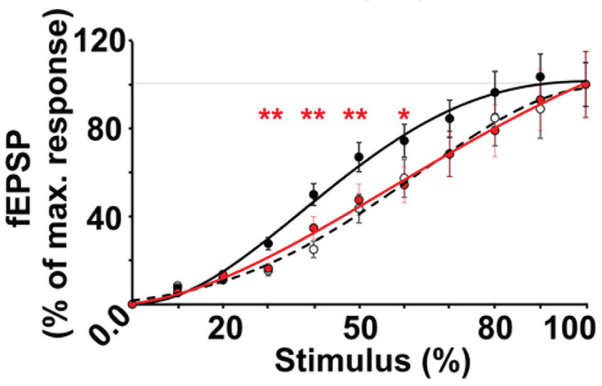

E

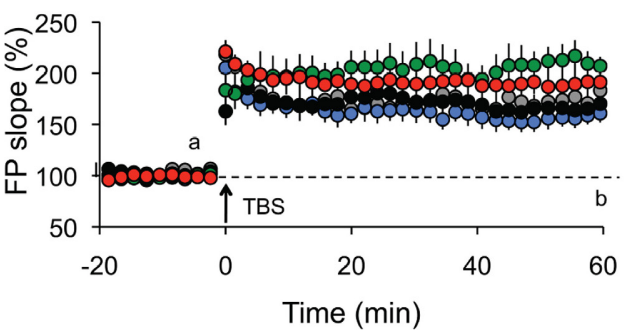

FIGURE 2 | Panx1 channels modulate neuronal excitability, synaptic transmission and plasticity in hippocampal slices. (A,B) Metabolic autocrine regulation of neuronal activity via Panx 1 channels and adenosine. (A) Sample trace showing increased outward current upon reduced extracellular glucose (from 11 to $3 \mathrm{mM}$ ) and subsequent reversal to baseline with ${ }^{10}$ panx application $(100 \mu \mathrm{M})$ in CA3 pyramidal neurons. Bar graphs showing the reversal of reduced glucose-induced outward current amplitude with ${ }^{10}$ panx (left), and that pretreatment with ${ }^{10}$ panx prevented reduced glucose-induced outward current. ${ }^{* *} p<0.01$. (B) Schematic showing a proposed model of purinergic autocrine regulation in CA3 pyramidal neurons. When $[A T P]_{i}$ is sufficient (1), low [Glucose] (2) induces ATP release from Panx1 channels on neurons (3). ATP is then dephosphorylated to adenosine (4) which activates adenosice $A_{1} R$ rceptors (5). $K_{\text {ATP }}$ channels are then opened leading to a decrease in neuronal excitability. (C-F) Panx1 regulates synaptic transmission, LTP and LTD. (C) Input-Output curves showing increased synaptic transmission in Pan $\times 1^{-/-}$(black line) compared to control Pan $\times 1^{+/+}$(dashed line) mice. Such effect was abolished in Pan $\times 1^{-/-}$
B

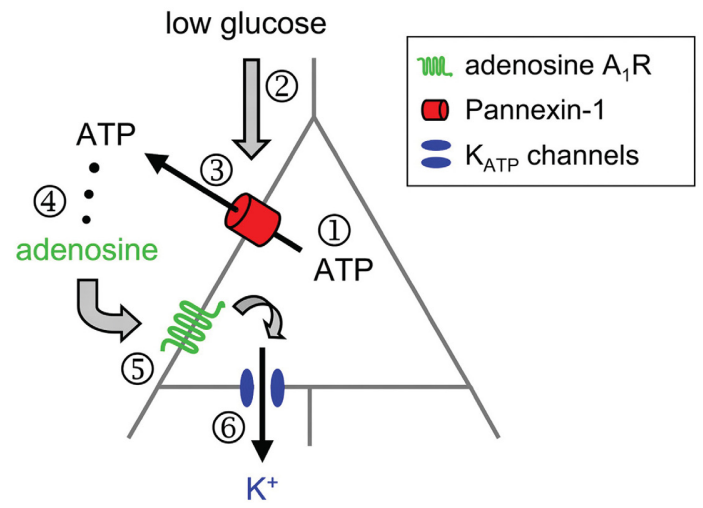

D

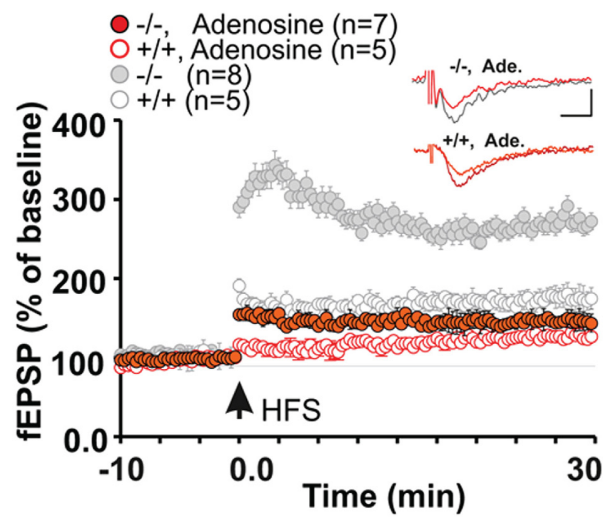

$\mathbf{F}$

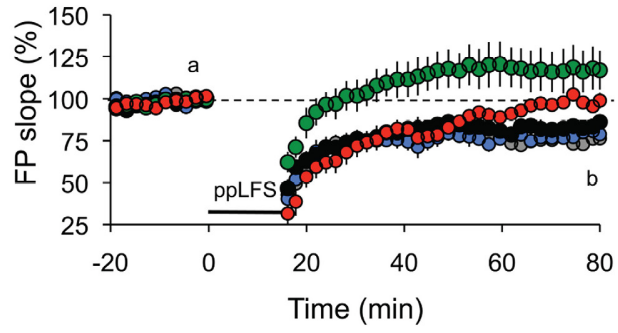

slices treated with $3 \mu \mathrm{M}$ adenosine (red line). ${ }^{*} p<0.01 ;{ }^{* *} p<0.001$. (D) LTP evoked by high frequency stimulation (four trains of 10 shocks at $100 \mathrm{~Hz}$ every $1 \mathrm{~s}$; HFS) is enhanced in Panx $1^{-/-}$(filled gray) compared to control Pan $\times 1^{+/+}$(open gray) mice. Adenosine treatment in Pan $\times 1^{-/}$slices (filled red) restores LTP levels to that of untreated control mice. Figure insets illustrate responses before and $30 \mathrm{~min}$ post HFS. Scale bar: $0.5 \mathrm{mV}, 10 \mathrm{~ms}$. (E) LTP induced by the delivery of theta burst stimulation protocol (TBS) is increased in adult Pan $\times 1^{-/-}$(green) compared to Pan $\times 1^{+/+}$(black) mice, whereas no difference was observed between young mice $(+/+$, gray; $-/-$, blue). In the presence of $100 \mu \mathrm{M}$ probenecid (Panx1 channel blocker; red), only transient LTP was enhanced. (F) Similarly, LTD induced by paired-pulse low frequency stimulation protocol $(1 \mathrm{~Hz}$ for $15 \mathrm{~min}$; PP-LFS) are impaired in adult Pan $\times 1^{-/-}$(green) compared to Pan $\times 1^{+/+}$(black) mice, whereas no difference was observed between young equivalent $(+/+$, gray; $-/-$, blue). In the presence of $100 \mu \mathrm{M}$ probenecid, only a transient LTD was observed. Adapted, with permission, from Kawamura et al. (2010) (A,B), Prochnow et al. (2012) (C,D) and Ardiles et al. (2014) (E,F). 
and information processing (Perea et al., 2009; Dallerac et al., 2013; Pannasch and Rouach, 2013). Whether this could be conducted via astroglial HC activity was first investigated in 2012. In particular, a possible role of HCs in learning and memory was reported (Stehberg et al., 2012). The authors selectively blocked Cx43 HCs using TAT-Cx43L2. This peptide was designed to interfere with the intracellular loop/tail interactions of Cx43 necessary for its $\mathrm{HC}$ but not gap-junctional activities (Ponsaerts et al., 2010). After microinfusion of TAT-Cx43L2 into the rat basolateral amygdala, an area of the brain associated with emotional memory (Ledoux, 2007), amnesia for auditory fear conditioning was observed (Figures 3A,B). This effect was found to be specific to memory consolidation, as the blocker applied $6 \mathrm{~h}$ after learning did not lead to memory deficits. Their results were corroborated using Gap27, a peptide commonly used to block Cx43 HC activity extracellularly, further suggesting specific contributions from $\mathrm{Cx} 43 \mathrm{HCs}$. In order to investigate the molecular mechanisms involved, a cocktail of gliotransmitters containing glutamate, glutamine, lactate, D-Serine, glycine, and ATP was coinfused with TAT-Cx43L2. As a result, a rescue of the memory defect was observed (Figure 3B). Since they showed that TATCx43L2 had no effect on ATP and glutamate release in neuronal cultures, and that $\mathrm{Cx} 43$ was found on astrocytes but not neurons, the authors concluded that the effect was specific for astroglial
A

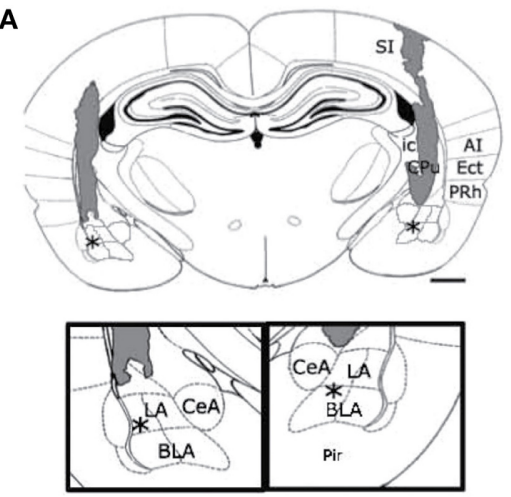

C

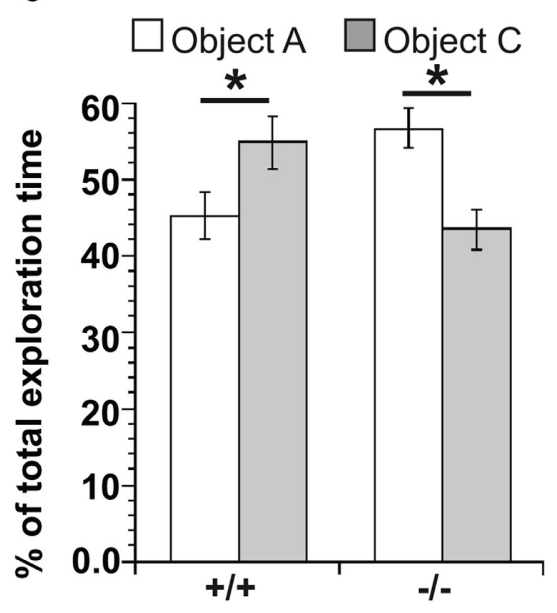

FIGURE 3 | Cx HCs and Panx1 channels have significant roles in learning and memory. (A,B) $\mathrm{C} \times 43 \mathrm{HC}$ function is required in fear conditioning memory consolidation. (A) Diagram showing site of microinfusions of the TAT-CX43L2, a selective $\mathrm{C} \times 43 \mathrm{HC}$ blocker, into the basolateral amydala (BLA). Asterisks indicate the tips of injection cannula (shaded regions). Enlargement is shown in insets. LA, lateral amygdala; $\mathrm{CeA}$, central amygdala; $\mathrm{SI}$,

somatosensory primary; PRh, perirhinal; Ect, ectorhinal; Pir, piriform; and Al, auditory primary cortices; $\mathrm{CPu}$, caudoputamen; ic, internal capsula. Scale bar: $1 \mathrm{~mm}$. (B) Fear conditioning memory was tested by first training rats to associate a tone with a foot shock. Their memory of this association was then assessed by how long they remain immobile (freeze) in response to the same tone alone $24 \mathrm{~h}$ later. TAT-C $\times 43 \mathrm{~L} 2(10 \mathrm{nM})$ microinfusion prior to training impaired fear conditioning memory (decreased in freezing time) compared to control. Such effect was rescued by co-microinfusion of a mixture of

B

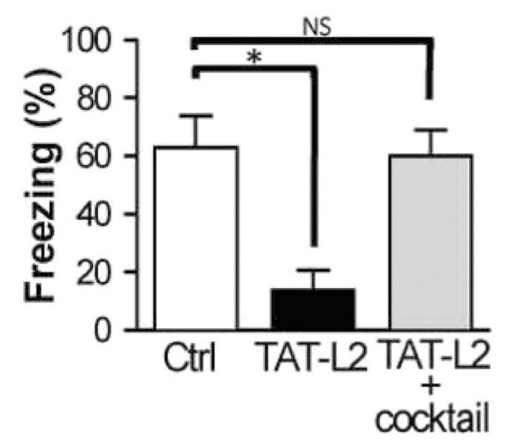

D

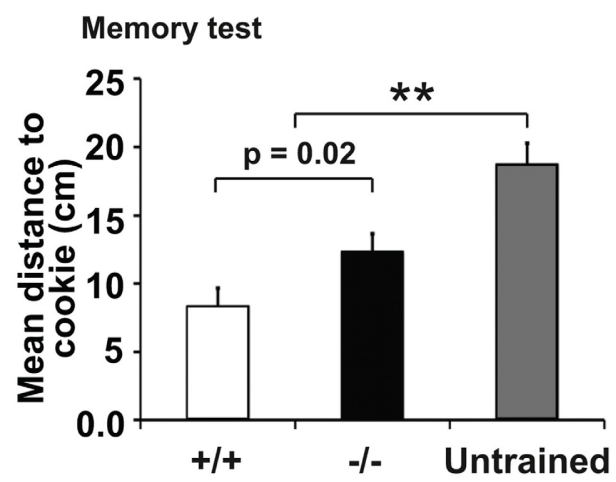

gliotransmitters including D-serine, glutamate, glutamine, glycine, ATP, and lactate (cocktail) rescued such effect. (C,D) Panx1 deletion leads to dysfunctions in learning and memory. (C) To assess object recognition, mice were allowed to explore two novel objects ( $A$ and $B$ ) for $5 \mathrm{~min}$. $1 \mathrm{~h}$ later, they were allowed to explore the familiar object $A$ together with a novel object $C$. Pan $\times 1^{-/-}$mice spent more time on object $A$ than $C$ compared to Pan $\times 1^{+/+}$ mice which did the opposite, indicating a deficit in object recognition. (D) Another memory test was carried out where mice were trained to remember locations of hidden cookies which were later removed. During the test, Pan $\times 1^{-1-}$ mice explored locations further from the original locations of cookies compared to the Pan $\times 1^{+/+}$mice but not as far as the untrained mice, indicating an impairment but not abolishment in memory. ${ }^{*} p<0.05$;

${ }^{* *} p<0.001$. Adapted, with permission, from Stehberg et al. (2012) (A,B) and Prochnow et al. (2012) (C,D) 
gliotransmitter release. This pioneer in vivo study has suggested an important contribution of gliotransmitter release via $\mathrm{Cx} 43$ HCs, presumed to be of astrocytic origin, in memory consolidation. However, it still remains elusive which gliotransmitters are involved and their downstream targets. Furthermore, direct release of such gliotransmitters via $\mathrm{Cx} 43 \mathrm{HCs}$ is yet to be demonstrated, as there are also other possible mechanisms like vesicular exocytosis (Parpura et al., 2004), Panxs (Iglesias et al., 2009), P2X7 channels (Suadicani et al., 2006), Bestrophin 1 (Han et al., 2013), and volume-regulated anion channels (Kimelberg, 2004), which could be downstream effects to $\mathrm{Cx} 43 \mathrm{HC}$ activation.

Shortly following the study by Stehberg and colleagues, another report linking $\mathrm{HC}$ activities to learning and memory was revealed. This time, the focus was on Panx channels and their well-characterized role in purinergic signaling. Since Panx1 is strongly expressed in postsynaptic terminals (Zoidl et al., 2007) and presumably also in astrocytes (Iglesias et al., 2009), this study explored the contributions of Panx1 to synaptic plasticity, which in turn may influence learning. Prochnow and colleagues have observed that in Panx1-/- hippocampus, neurons have increased synaptic transmission and enhanced longterm potentiation (LTP) triggered by high frequency stimulation (Prochnow et al., 2012), as shown in Figure 2D. Interestingly, these changes in neuronal properties could be rescued by supplying extracellular adenosine, a metabolite of ATP, as well as blockage of postsynaptic NMDARs, indicating that this process involves Panx1-mediated ATP release and an inhibition of glutamatergic excitatory responses. They have also found that only in adult mice, an upregulation of mGluR4 accompanies chronic deletion of Panx1, which accounted for the enhanced persistent LTP observed. The authors suggested that this might be an adaptive compensatory response to the enhanced neuronal transmission. Consequently, these modifications in $\mathrm{Panx}^{-/-}$mice led to behavioral defects like altered sensory motor gating capabilities, assessed using pre-pulse inhibition of the acoustic startle response, which may reflect stress and anxiety. Cognitively, novel object recognition (Figure 3C) and spatial learning involving the location of a treat were also impaired (Figure 3D). These deficits were expected, since it has been shown that saturation of LTP is related to impaired learning (Moser et al., 1998). Indeed, this study demonstrated that ATP released through Panxl channels participates in maintaining synaptic strength and plasticity in hippocampal CA1 neurons, and in turn plays a role in learning and memory. Furthermore, the authors suggested that Panx1 mediates a feedback response through presynaptic activation of adenosine A1 receptors and inhibition of glutamate release, which is essential in cognitive functioning. However, this study did not distinguish between neuronal and glial Panx1 channels. Given that astrocytes are thought to also express ATP-releasing Panx1 channels (Iglesias et al., 2009) and that they have been implicated in the modulation of neuronal activities (Dallerac et al., 2013), it is of interest to determine specific astrocytic contributions in these behavioral and cognitive processes, possibly with the use of conditional knockouts.

Interestingly, very recently, another study showed that not only LTP but also long-term depression (LTD) is altered in Panx1 ${ }^{-/-}$mice (Ardiles et al., 2014). Specifically, they observed that LTD was impaired in either Panx1 ${ }^{-/-}$hippocampus or during pharmacological blockage of Panxl channels. Moreover, they have also demonstrated that both the enhancement in LTP and impairment in LTD were only observed in adult but not in young Panx $1^{-/-}$mice (Figures $\left.2 E, F\right)$. This study revealed that Panx1, which may be of neuronal or glial origin, participates in bidirectional synaptic plasticity by modulating both potentiation and depression in an age-dependent manner. Thus, the authors suggested that Panxl channels may influence learning and memory in adults by restraining the threshold for the induction of synaptic plasticity. The functional significance of this age-dependent bidirectional regulation, however, is yet to be explored.

\section{VISION}

In addition to their contributions to synaptic and higher level brain functions, some fundamental visual processes have also been shown to be mediated by $\mathrm{Cx}$ HCs and Panx channels. In particular, two groups have demonstrated the involvement of these channels in visual processes in zebrafish. Between the two channels, Cx HCs were first implicated in synaptic transmission essential for vision (Kamermans and Fahrenfort, 2004; Klaassen et al., 2011). In the retina, Cx52.6 and Cx55.5 form GJ channels between horizontal cells, while Cx55.5 also form HCs at the tips of the horizontal cell dendrites and can open at physiological membrane potentials (Shields et al., 2007). Klaassen et al. (2011) generated zebrafish Cx55.5 mutant, with a stop codon in the first extracellular loop of Cx55.5 (C54X), which led to decrease in both, Cx55.5 expression on the tips of the horizontal cell dendrites, and HC currents from horizontal cells. They reported that the total gap-junctional surface was preserved, although alterations in Cx52.6 expression and in the general organization of gap-junctional plaques were found. This study investigated the negative feedback from horizontal cells to cones, essential for contrast enhancement in vision. In these mutants, light-induced feedback from horizontal cells to cones was significantly reduced (Figure 4A). As a consequence, these mutant zebrafishes exhibited impairment in contrast sensitivity (Figure 4B). Supported by a mathematical model, the authors suggested that current flowing through Cx HCs at the tips of horizontal cell dendrites actually exert an ephaptic modulation of synaptic transmission through activation of adjacent voltage-dependent $\mathrm{Ca}^{2+}$ channels in presynaptic photoreceptor terminals. Interestingly, they also reported an upregulation of Panx1 expression at the tips of the horizontal cell dendrites in these mutants, suggesting that it could be partly accountable for the residual $40 \% \mathrm{HC}$ activity in the mutant. The same group later demonstrated that $\mathrm{Cx} 55.5 \mathrm{HC}$ currents possess an inward component that is active at physiological membrane potentials and extracellular $\mathrm{Ca}^{2+}$ levels (Sun et al., 2012). These studies suggest an unconventional role of horizontal cell $\mathrm{Cx} \mathrm{HCs}$ in synaptic transmission in the retina, where a carp ortholog of mammalian Cx43 is also expressed among several other Cxs (Dermietzel et al., 2000). While similar mechanisms involving other Cxs and other CNS regions are yet to be investigated, these research findings further confirmed the dynamic nature of physiological roles of HCs in synaptic transmission leading to functional outcome, which in this case is visual acuity. 
A
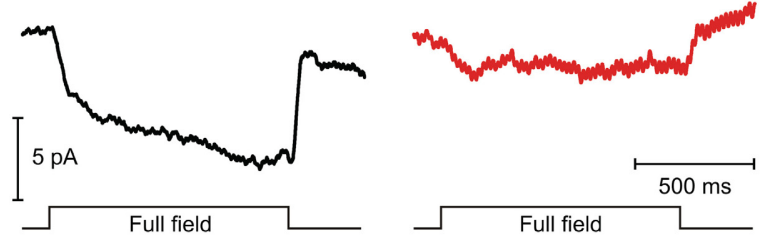

B

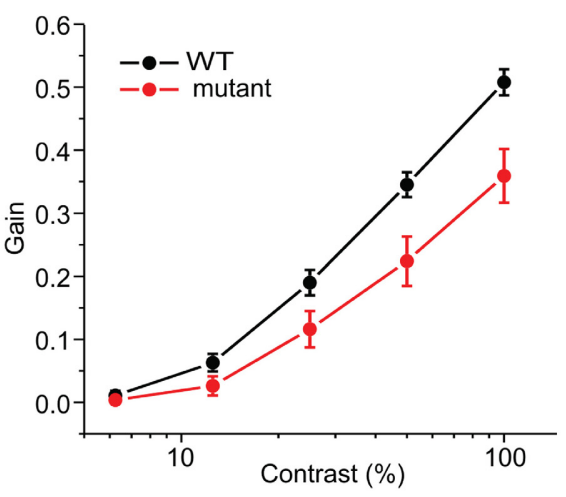

C

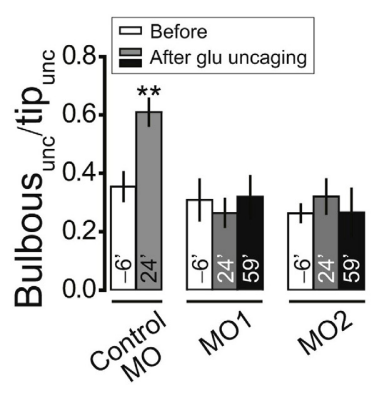

D

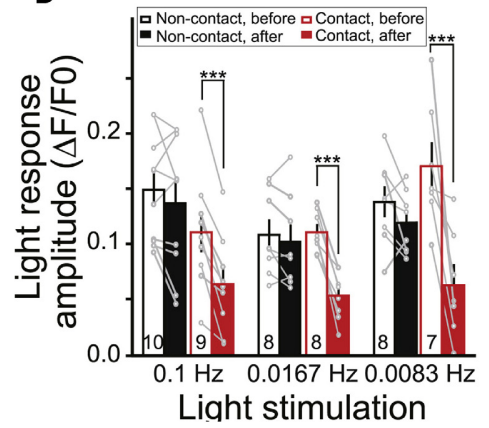

E

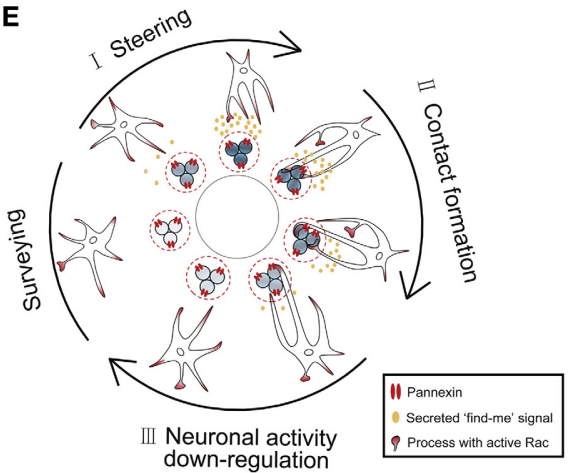

FIGURE 4 | Cx HCs and Panx1 channels have significant roles in synaptic transmission essential for vision. (A,B) $\mathrm{C} \times 55.5 \mathrm{HCs}$ are important for contrast sensitivity in zebrafish retina. (A) To measure light-induced feedback responses, cones were first saturated with a $20 \mu \mathrm{m}$ spot of light. A full-field light flash induced an inward current in cones due to negative feedback from horizontal cells. Cx55.5 mutant (red) cones showed a decreased feedback response compared to wild-type (black), as shown in sample traces. (B) Optokinetic gain, as a measure of contrast sensitivity, was determined by dividing the eye movement velocity by the velocity of the stimulus over a range of contrast in zebrafish larvae. This was significantly decreased in mutant compared to wild-type zebrafish. (C-E) Reciprocal regulation between resting microglia and neuronal activity via Panx1 channels. (C) Glutamate uncaging was performed in the intact zebrafish larvae to evoke $\mathrm{Ca}^{2+}$ activities of tectal neurons within $20 \mu \mathrm{m}$ around the uncaging point of $1 \mu \mathrm{m}$ in the soma layer of the optic tectum. From the side of microglia facing the uncaging point ("unc"), the proportion of the number of bulbous normalized to all process tips ("Bulbousunc $/ T i p_{u n c}$ ") is shown for larvae injected with splice morpholino oligonucleotides (MO) 6-min before (clear) and 24-min (gray) and 59-min (black) after uncaging. The increased in bulbous endings is shown in control MO, but abolished in Panx1 expression downregulation MO1 and MO2. (D) Normalized intensities of $\mathrm{Ca}^{2+}$ activities (light response amplitude) of tectal neurons in vivo evoked by moving bars at indicated frequencies are shown. Response is significantly reduced in neurons after microglial contact (red filled vs. clear bars) as compared to non-contact (black filled vs. clear bars). Numbers of neurons examined are shown on bars. (E) Schematic diagram showing a proposed model of microglial modulations of neuronal activity via Panx1 channels. During neuronal activity, neurons secrete "find me" signal locally (ATP being a candidate) via Panx 1 channels, which steer microglial processes toward them (from "Surveying" to "I"). Bulbous endings are then formed on these processes promoting contact with neurons ("II"). Upon such contact, neuronal activity is downregulated ("III"). ${ }^{* *} p<0.01 ;{ }^{* * *} p<0.001$. Adapted, with permission, from Klaassen et al. (2011) (A,B), Li et al. (2012) (C,D).
Another study revealed that neuronal activity in the optic tectum of larval zebrafish could modulate motility of resting microglia toward active neurons via Panxl channels (Li et al., 2012). This in turn downregulates both spontaneous and visually-evoked neuronal activities under physiological condition. Specifically, using in vivo imaging techniques and local glutamate uncaging, the authors observed an enhanced formation of microglial processes with bulbous endings, which contact active neurons (Figure 4C). This was blocked by probenecid and CBX, as well as by injection of oligonucleotides which downregulate Panxl expression, suggesting a potential contribution of Panx1 channel activity. As Panxl-mediated currents were recorded in tectal neurons but not in microglia, they concluded that this was due to the opening of neuronal Panxl channels. The possible downstream involvement of ATP and P2 receptors was also tested. As a result, similar abolishment of activity-induced microglial bulbous ending formation was found in the presence of apyrase, an ATP-hydrolyzing enzyme, and suramin, a P2 receptor blocker. Remarkably, while microglia was found to preferentially contact neurons with initially high levels of spontaneous activity, the authors discovered that this spontaneous activity was reduced upon microglia-neuron contact. In addition, moving bar-evoked $\mathrm{Ca}^{2+}$ activity in these neurons was also decreased upon microglial contact (Figure 4D). These results suggest an interesting reciprocal modulation between neurons and microglia via neuronal Panx1 channels and ATP/P2 receptors (Figure 4E). The involvement of ATP as a "find-me" signal was expected, as activated microglia can be attracted toward sites of brain injury by ATP (Davalos et al., 2005). However, direct evidence of ATP release via Panx1 is yet to be shown. The authors postulated that since microglial processes mainly contact the soma, but not dendrites, of tectal neurons, such contact-induced downregulation 
is due to reduction of neuronal excitability rather than synaptic inputs.

\section{CONCLUSIONS, REMAINING QUESTIONS AND FUTURE DIRECTIONS}

Unlike in pathology, the functional roles of $\mathrm{Cx}$ HCs and Panxs in physiological situations have only recently been considered and explored. This review summarizes the latest studies supporting their neurophysiological relevance in the CNS. In particular, aspects concerning development, glucose sensing, synaptic transmission and plasticity, learning and memory, as well as vision are discussed (Table 2). One of the first studies showed that ATP is released via $\mathrm{Cx} 43 \mathrm{HCs}$ from retinal pigment epithelial cells, which promotes division and proliferation of progenitor cells in the developing retina (Pearson et al., 2005). In the hypothalamic tanycytes, the same HC subtype contributes to the uptake of extracellular glucose, triggering downstream $\mathrm{Ca}^{2+}$ response via ATP release (Orellana et al., 2012a). Moreover, ATP released via $\mathrm{Cx} 43 \mathrm{HCs}$ in astrocytes was found to increase hippocampal excitatory transmission via P2 receptors (Chever et al., 2014). Upon decrease in extracellular $\mathrm{Ca}^{2+}$ levels, however, ATP released from astrocytic $\mathrm{Cx} 43 \mathrm{HCs}$ may also participate in the generation of feedback inhibitory transmission in hippocampal interneurons (Torres et al., 2012). Functionally, these channels have also been shown to play a role in fear memory consolidation in adult rats (Stehberg et al., 2012). Apart from Cx43, Cx55.5 HCs located at the tips of retinal horizontal cell dendrites were also found to conduct light-induced feedback transmission between horizontal cells and cones, and as a functional consequence, enhance contrast sensitivity of the eye (Klaassen et al., 2011). Similar to Cx43 HCs, ATP release from Panxl channels was found to promote neurogenesis in the postnatal mouse ventricular zone (Wicki-Stordeur et al., 2012), as well as trigger a dowregulation of neuronal excitability upon decrease in extracellular glucose in the hippocampus (Kawamura et al., 2010). Interestingly, also in the hippocampus, they reduce synaptic transmission and exert an age-dependent bidirectional control (decreasing LTP while increasing LTD) over synaptic plasticity (Prochnow et al., 2012; Ardiles et al., 2014). In the zebrafish, Panxl channels were found to be involved in promoting microglial motility toward active neurons, leading to a decrease in neuronal activity related to vision ( $\mathrm{Li}$ et al., 2012). Lastly, they have also been shown to be important for sensorimotor gating, as well as object recognition and spatial memory (Prochnow et al., 2012). Taken together, these important studies suggest that $\mathrm{Cx}$ HCs and Panxs are not only open during physiological conditions, but also play important and dynamic roles in a variety of neurophysiological processes and behavior. With these encouraging findings, it is expected that more future evidence will emerge to strengthen the physiological relevance of these large pore membrane channels in the CNS. However, in order to achieve this, some important issues need to be considered and addressed.

\section{WHAT ARE THE COMPOSITION OF FUNCTIONAL HCS AND SUBSTANCES RELEASED?}

Current understanding of the physiological roles of $\mathrm{Cx}$ HCs and Panx channels is largely focused on two specific subtypes, namely
Cx43 and Panx1, both permeable to ATP. The lack of focus on other channel isoforms however does not rule out their potential contributions in physiology. Although Torres et al. (2012) have shown that $\mathrm{Cx} 30$ does not account for the hippocampal defects that they observed in $\mathrm{Cx} 30 / \mathrm{Cx} 43$ double knockout mice, it is unclear whether $\mathrm{Cx} 30$ has any HC-specific effect on neurotransmission. Indeed, one major difficulty in the study of HCs is the lack of experimental tools with high isoform selectivity, as well as specificity for HCs over GJ channels. For instance, the pharmacological blocker CBX acts on Cx HCs and Panx channels, as well as on GJs (Schalper et al., 2008). Similarly, Gap26/27, which are mimetic peptides commonly used to block $\mathrm{Cx} 43 \mathrm{HCs}$, can also affect GJ channels when applied for several hours (Samoilova et al., 2008). Nevertheless, a few inhibitors that block HCs but not GJs, such as Gap19/TAT-Gap19 and TAT-L2 (see Table 1), have been developed (Ponsaerts et al., 2010; Wang et al., 2013b). Therefore, advances in the generation of more specific mimetic peptides and even antibodies (Riquelme et al., 2013) should improve selectivity among HC isoforms. Transgenic organisms with impairment in either gap-junctional or HC functions would also be ideal. Furthermore, it is interesting that most of the studies described in this review have demonstrated effects mediated by ATP release or its metabolite, adenosine. As HCs are also permeable to signaling molecules like $\mathrm{NAD}^{+}$, glutamate, glutathione and prostaglandin E2 (Wang et al., 2013a), which are known to be important for synaptic activity and cognitive functions, it is of interest to expand our search toward the effect of the release of these substances.

\section{WHERE ARE FUNCTIONAL HCs LOCATED?}

The fact that physiologically active HCs are detected in a number of cell types ranging from stem cells to neurons and glia implies their ubiquitous functions in the CNS (see Table 2). In fact, $\mathrm{Cx} 43$ proteins are largely expressed in vessels (Simard et al., 2003; Rouach et al., 2008) and supposedly near synapses (Ormel and Gundersen, 2011), suggesting their roles as regulators of synaptic activity, vasomotricity and hyperemia. In addition, their preferential expression on astrocytes facilitates their roles in astroglial network excitability, mediating paracrine (Torres et al., 2012) and autocrine regulations within astrocyte network (Wang et al., 2013a). Some neurons also express HC proteins like Cx36 in GABAergic interneurons or Panxs in pyramidal neurons, but their properties as HCs in vivo is still under investigation. Furthermore, both $\mathrm{Cx}$ HCs and Panx1 channels have also been found to be expressed on microglia and oligodendrocytes with activities associated with pathological ATP and glutamate release, as well as ion gradient imbalance (Orellana et al., 2011c). Their functions in physiology, however, are yet to be explored.

Other than cell-type specific expression, it is also unclear in which subcellular domain functional HCs are present. For instance, $\mathrm{Cx} 43 \mathrm{HCs}$ expressed on astroglial plasma membranes have been thought to serve as a reserve pool for GJ formation. Thus, it has been a challenge to differentiate between functional HCs and those presented on the membrane for GJ activities using only immunostaining. The development of new techniques and tools to not only study, but to also visualize the location of active HCs, is therefore warranted. We have recently shown that 
Table 2 | Roles of connexin hemichannels and pannexin channels in neurophysiology.

\begin{tabular}{|c|c|c|c|c|}
\hline Function & $\begin{array}{l}\text { Channel } \\
\text { subtype }\end{array}$ & Proposed mechanisms & Experimental models and tools & References \\
\hline \multicolumn{5}{|c|}{ DEVELOPMENT AND GLUCOSE SENSING } \\
\hline \multirow[t]{2}{*}{$\begin{array}{l}\uparrow \text { Cell division } \\
\text { and proliferation }\end{array}$} & $\mathrm{C} \times 43$ & $\begin{array}{l}\text { ATP released from RPE cells via } \mathrm{C} \times 43 \mathrm{HCs} \\
\text { triggers } \mathrm{Ca}^{2+} \text { waves through } \mathrm{RPE} \text { cells and } \\
\text { stimulates } \mathrm{P} 2 \text { receptors on retinal } \\
\text { progenitor cells }\end{array}$ & $\begin{array}{l}\text { Isolated neural retina from chick embryos } \\
\text { Pharmacological blocker (Carbenoxolone); } \\
\text { mimetic peptide (Gap26) }\end{array}$ & Pearson et al., 2005 \\
\hline & Panx1 & $\begin{array}{l}\text { ATP released via Panx } 1 \text { channels stimulates } \\
\text { NSC/NPC via P2 receptors }\end{array}$ & $\begin{array}{l}\text { Neuro2a neuroblastoma cell line, cultures of } \\
\text { postnatal mouse ventricular zone NSC/NPCs } \\
\text { Pharmacological blocker (Probenecid); Panx1 } \\
\text { siRNA }\end{array}$ & $\begin{array}{l}\text { Wicki-Stordeur et al., } \\
2012\end{array}$ \\
\hline
\end{tabular}

\section{(2) Glucose sensing and signal transduction}

$\uparrow$ Hypothalamic Cx43 Glucose uptake and glycolysis opens Cx43 glucose-sensing $\mathrm{HCs}$ allowing the release of ATP, which activates local $\mathrm{P} 2 \mathrm{Y} 1$ receptors and $\left[\mathrm{Ca}^{2+}\right]_{i}$ increase
Cultured rat hypothalamic tanycytes

Pharmacological blockers (La ${ }^{3+}, \mathrm{C} \times 43^{\mathrm{E} 2}$,

Probenecid); mimetic peptides (Gap26, ${ }^{10}$ panx)
Orellana et al., 2012a

Acute hippocampal slices from juvenile rats

Kawamura et al., 2010

Pharmacological blocker (Carbenoxolone, Octanol); mimetic peptide ( ${ }^{10}$ panx)

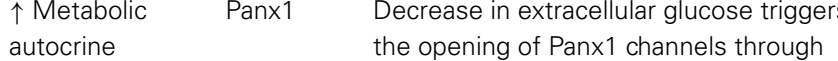

regulation which ATP is released

\section{SYNAPTIC TRANSMISSION AND PLASTICITY}

\section{(1) Neuronal excitability and synaptic transmission}

$\uparrow$ Synaptic Cx43 transmission
ATP released via $\mathrm{C} \times 43 \mathrm{HCs}$ in astrocytes promotes excitatory synaptic transmission via $\mathrm{P} 2$ receptors
Acute hippocampal slices from juvenile mice

Acute hippocampal slices from juvenile mice depolarization and firing of inhibitory interneurons and a slow $\mathrm{Ca}^{2+}$ wave in astrocytes both via $\mathrm{P} 2 \mathrm{Y}$ receptors
Transgenic mice: CX43 $3^{f / f l}:$ hGFAP-Cre $=$

Astrocytic Cx43 conditional knockout; pharmacological blocker (Carbenoxolone), mimetic peptide (Gap26, ${ }^{10}$ panx)

Torres et al., 2012

Transgenic mice: (1)

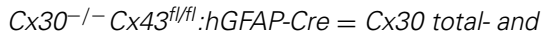

CX43 astrocytic conditional knockout; (2)

$C \times 30^{-1}-C \times 43^{f l / f l}=C \times 30$ total knockout; and 3)

CX43+/G138Rfl.hGFAP-Cre mice = enhanced

astrocytic $\mathrm{C} \times 43 \mathrm{HC}$ activity; pharmacological blocker (Carbenoxolone)

Chever et al., 2014

Acute hippocampal slices from juvenile rats

Kawamura et al., 2010 Pharmacological blocker (Carbenoxolone, Octanol); mimetic peptide ( ${ }^{10}$ panx) $\downarrow$ Neurona
excitability

Panx1
Decrease in extracellular glucose triggers the opening of Pan $\times 1$ channels through which ATP is released. Its metabolite adenosine then activates adenosine $\mathrm{A} 1$ receptors and opens $K_{\text {ATP }}$ channels leading to decreased neuronal excitability

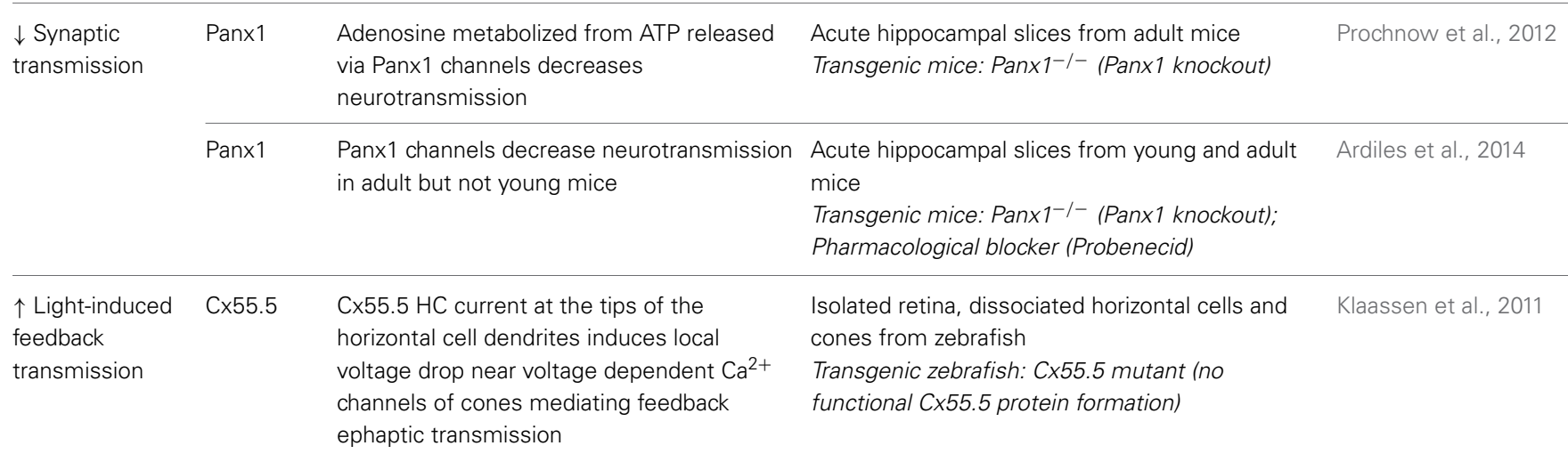


Table 2 | Continued

\begin{tabular}{llll}
\hline Function & $\begin{array}{l}\text { Channel } \\
\text { subtype }\end{array}$ & Proposed mechanisms & Experimental models and tools \\
\hline $\begin{array}{l}\downarrow \text { Spontaneous } \\
\text { neuronal activity }\end{array}$ & Panx1 & $\begin{array}{l}\text { Panx1 channels on active neurons promote } \\
\text { microglial motility via ATP/P2 receptors, } \\
\text { which in turn downregulates spontaneous } \\
\text { neuronal activity }\end{array}$ & $\begin{array}{l}\text { Pharmacological blocker (Carbenoxolone, } \\
\text { oligonucleotides }\end{array}$ \\
& & & Li et al., 2012 \\
\hline
\end{tabular}

\section{(2) Synaptic plasticity \\ $\downarrow$ LTP Panx1}

via Panx1 channels suppresses the

induction of LTP

$\downarrow$ LTP, $\uparrow$ LTD $\quad$ Panx1
Panx 1 channels control the threshold of the bidirectional induction of synaptic plasticity in adult but not in young mice
Acute hippocampal slices from adult mice

Prochnow et al., 2012 Transgenic mice: Pan $\times 1^{-1-}$ (Panx1 knockout); Pharmacological blocker (mefloquine)
Acute hippocampal slices from young and adult Ardiles et al., 2014 mice

Transgenic mice: Panx1-/- (Panx1 knockout);

Pharmacological blocker (Probenecid)

\section{INTEGRATIVE FUNCTIONS}

\section{(1) Sensorimotor gating}

$\downarrow$ Sensorimotor Panx1

gating

Panx1 channels inhibit pre-pulse inhibition of Mice (adult)

the acoustic startle response

Transgenic mice: Panx $1^{-/-}$(Panx1 knockout)
Prochnow et al., 2012

capabilities

\section{(2) Learning and memory \\ $\uparrow$ Fear memory Cx43} consolidation
Gliotransmitters release through astrocytic $\mathrm{C} \times 43 \mathrm{HCs}$ promotes the consolidation of fear memory

\section{Rats (adult)}

Mimetic peptides injection into basolateral amygdala (Gap26, TAT-CX43L2)

\begin{tabular}{llll}
\hline $\begin{array}{l}\uparrow \text { Object } \\
\text { recognition } \\
\text { memory }\end{array}$ & Panx1 & $\begin{array}{l}\text { Panx1 channels improve the ability of a } \\
\text { mouse to recognize an object as familiar }\end{array}$ & $\begin{array}{l}\text { Mice (adult) } \\
\text { Transgenic mice: Panx1-/- (Panx1 knockout) }\end{array}$ \\
\hline $\begin{array}{l}\uparrow \text { Spatial } \\
\text { memory }\end{array}$ & Panx1 & $\begin{array}{l}\text { Panx1 channels enhance the ability of a } \\
\text { mouse to remember the location of a treat }\end{array}$ & $\begin{array}{l}\text { Mice (adult) } \\
\text { Transgenic mice: Panx } 1^{-/-} \text {(Panx1 knockout) }\end{array}$ \\
\hline
\end{tabular}

\section{(3) Vision}

$\uparrow$ Contrast

sensitivity

Zebrafish larvae

Transgenic zebrafish: Cx55.5 mutant zebrafish (no functional CX55.5 protein formation)

\begin{tabular}{lll}
\hline$\downarrow$ & Panx1 & Microglial contact promoted by Panx1 \\
Visually-evoked & & channels on active neurons via ATP/P2 \\
neuronal activity & receptors downregulates evoked neuronal \\
& activity
\end{tabular}

Zebrafish larvae

Pharmacological blocker (Carbenoxolone,

Probenecid); Panx1 downregulation

oligonucleotides

CX, Connexin; fl, floxed; HC, hemichannel; G138R, single point mutation of glycine 138 to arginine of CX43; LTD, long-term depression; LTP, long-term potentiation; NSC/NPS, neural stem cells and progenitor cells; Panx, Pannexin; RPE, retinal pigment epithelium.

astrocytes can extend their fine processes near or even within synaptic clefts (Pannasch et al., 2014), suggesting that the expression of functional HCs on these processes would allow them to more efficiently modulate neuronal transmission due to their proximity to targeted sites. Finally, if HCs are concentrated on subcellular domains, it would be interesting to investigate how they are targeted and trafficked to these locations.

\section{WHEN ARE HCS OPEN?}

While numerous in vitro studies have been performed to characterize the biophysical properties of these large membrane pores and to determine aspects that would trigger their opening, HC activation in situ or in vivo, particularly during physiological conditions, is less understood. Torres et al. (2012) proposed that the increase in glutamate and decrease in extracellular $\mathrm{Ca}^{2+}$ occurring during synaptic transmission favor astroglial Cx43 HC opening, suggesting that the conductance or open probability or number of active channels, or possibly recruitment of HCs near synaptic cleft, is dependent on neuronal activity. Although they also used high frequency stimulation to mimic neuronal activity, it is not clear as to whether these manipulations represent conditions in vivo and if the suggested mechanism is involved in the modulation of cognitive functions (Stehberg et al., 2012). Apart from extracellular $\mathrm{Ca}^{2+}$, an increase in intracellular $\mathrm{Ca}^{2+}$ within 
the physiological range has also been found to open $\mathrm{Cx} 43$ and Cx32 HCs, as assessed by ATP release and dye uptake (De Vuyst et al., 2006, 2009). On the other hand, studies on Panxl channels have reported cognitive and behavioral deficits in knockout mice (Prochnow et al., 2012). However, long-term effect due to chronic deletion of the gene cannot be ruled out. The development in the application of current techniques in vivo, especially those that allow acute manipulation or detection of channel opening and closing, would be useful for addressing these issues. More importantly, the use of such in vivo systems will offer the benefit of behavioral studies, cognitive tests as well as the characterization of developmental defects.

It is conceivable that, due to their large pore size and conductance, the opening of Cx HCs and Panx channels is different from other plasma membrane ion channels and likely requires tighter control to preserve cell integrity. This more stringent regulation could be related to minimizing channel opening duration. Perhaps various modulators could differentially open the same channel with different timescales. Transient channel opening to release substances in short pulses may also prevent a sudden loss of intracellular substances. In contrast, Cx HC and Panx channels opening might merely be a passive response toward transient changes in concentration gradients of molecules like glucose, lactate, or ATP in an activity-dependent manner contributing to the maintenance of basal homeostasis. Additionally, HCs are permeable to water and could play an important role in regulation of intracellular osmolarity and cell volume (Quist et al., 2000). To test these possibilities, it becomes essential to focus on the moment-to-moment action of HC activity on brain processes like neurotransmission.

\section{HOW ARE HC OPENING AND SUBSTANCE RELEASE REGULATED FOR DOWNSTREAM EFFECTS?}

HCs are rather non-selective large pore membrane channels which, if not regulated, could lead to loss of important intracellular molecules and more seriously cell death. Thus, the open probability of these channels, their membrane distribution, trafficking and proximity to target receptors are crucial aspects requiring tight controls. While the opening and closing of $\mathrm{Cx}$ GJ channels are tightly regulated (Dermietzel and Spray, 1993; Pannasch and Rouach, 2013), it is not well understood whether the same pathways also apply to HCs. More importantly, it is still unclear which molecular mechanisms underlie the formation of HCs over GJ channels and vice versa. It has been shown in pathological situations that GJ channels and HCs can display similar or opposite responses depending on differential activation of intracellular pathways. For example, lipopolysaccharide and basic fibroblast growth factor have been found to differentially influence Cx HCs and GJ channels (De Vuyst et al., 2007). In relation to this, aspects of how they are targeted to and maintained on plasma membranes as single channels are also fundamental to understand physiological HC properties.

Interestingly, Cx43 HCs and Panx1 channels seem to have opposite roles on neuronal activity and behavior. While Stehberg et al. (2012) showed that inhibiting Cx43 HCs with mimetic peptides in vivo strongly impaired fear memory consolidation, two other subsequent studies on $\mathrm{Panx}^{-/-}$mice demonstrated a strong enhancement in LTP and an abolishment in LTD (Prochnow et al., 2012; Ardiles et al., 2014). This suggests that Cx43 and Panx1 HCs are involved in two distinct neuromodulatory pathways. One can also argue that such differential effect might rely on differences in experimental models using acute blockage of $\mathrm{Cx} 43 \mathrm{HC}$ as opposed to Panx $1^{-/-}$mice with chronic deletion of channels. Indeed, the effects on LTP and LTD were not observed in young mice, but only in adults, in which they also observed a compensatory transcriptional up-regulation of metabotropic glutamate receptor 4, proposed to be due to chronic decrease in extracellular ATP. Furthermore, Stehberg et al. only showed that the release via $\mathrm{Cx} 43 \mathrm{HCs}$ involved one or more gliotransmitters, whereas Panx $1^{-/}$defects were specifically rescued by adenosine. This raises the questions of whether these HCs could exhibit cell-type specific regulations (in this case neurons vs. astrocytes) or even release different combinations of molecules under varying circumstances. In addition, the quantity of release and the proximity to targeted sites, as well as the nature and localization of receptors, also need to be taken into account. It is of great importance that such opposing effects between HC subtypes are clarified such that any differential modulations of downstream effects can be better understood. The use of global and conditional knockout systems will provide valuable insights into whether the observed effects are cell-type or developmentally specific. It would also be important to determine whether HC uptake and release of various transmitters, ions and metabolites are co-regulated and whether it is synergistic with other release pathways. This may enhance the efficiency of cell-tocell communication and allow dynamic actions on downstream mechanisms.

On a more complex level, it would be of great interest to determine if $\mathrm{HC}$ activity could display plasticity similar to postsynaptic glutamate receptors. It is probable that in response to neuronal activity, HC conductance or phosphorylation is altered leading to differential expression/presentation and distribution accross plasma membrane. Indeed, several Cx HCs, like Cx43 and Cx46, have been shown to have increased open probability depending on their phosphorylation state (Li et al., 1996; Ngezahayo et al., 1998; Sáez et al., 2005). Lastly, while most physiological actions of HCs thus far involve ATP release, it is necessary to clarify whether different channels indeed have specific and/or exclusive roles in certain biophysical processes contributing to neurotransmission and behavior. If so, what underlying mechanisms would allow them to be differentially regulated. As ATP is an important substance regulating neurotransmission and many basal processes, similar roles of HCs on other functions like hyperemia (Pelligrino et al., 2011) and brain oscillations (Schulz et al., 2012) are likely and yet to be characterized.

While there has been decades of research to establish the pathological contributions of HCs in the CNS, our understanding of their potential roles in physiological processes has just begun. Indeed, as more encouraging findings emerge, many fundamental issues must be addressed. Nevertheless, it is hoped that by unraveling the properties of these membrane channels in physiology, we will also be able to gain insights into their functions in pathologies and to explore their potential roles as therapeutic targets. 


\section{ACKNOWLEDGMENTS}

This work was supported by grants from the French Research Agency (ANR, Programme Blanc), City of Paris (Programme Emergence) INSERM, CNRS and Collège de France to Nathalie Rouach, Labex Memolife to Giselle Cheung and FRM (Fondation pour la Recherche Médicale) to Oana Chever.

\section{REFERENCES}

Amzica, F., Massimini, M., and Manfridi, A. (2002). Spatial buffering during slow and paroxysmal sleep oscillations in cortical networks of glial cells in vivo. J. Neurosci. 22, 1042-1053.

Anselmi, F., Hernandez, V. H., Crispino, G., Seydel, A., Ortolano, S., Roper, S. D., et al. (2008). ATP release through connexin hemichannels and gap junction transfer of second messengers propagate $\mathrm{Ca}^{2+}$ signals across the inner ear. Proc. Natl. Acad. Sci. U.S.A. 105, 18770-18775. doi: 10.1073/pnas. 0800793105

Ardiles, A. O., Flores-Muñoz, C., Toro-Ayala, G., Cárdenas, A. M., Palacios, A. G., Muñoz, P., et al. (2014). Pannexin 1 regulates bidirectional hippocampal synaptic plasticity in adult mice. Front. Cell Neurosci. 8:326. doi: 10.3389/fncel.2014.00326

Baranova, A., Ivanov, D., Petrash, N., Pestova, A., Skoblov, M., Kelmanson, I., et al. (2004). The mammalian pannexin family is homologous to the invertebrate innexin gap junction proteins. Genomics 83, 706-716. doi: 10.1016/j.ygeno.2003.09.025

Bargiotas, P., Krenz, A., Hormuzdi, S. G., Ridder, D. A., Herb, A., Barakat, W., et al. (2011). Pannexins in ischemia-induced neurodegeneration. Proc. Natl. Acad. Sci. U.S.A. 108, 20772-20777. doi: 10.1073/pnas.1018262108

Bennett, M. V., Garre, J. M., Orellana, J. A., Bukauskas, F. F., Nedergaard, M., and Sáez, J. C. (2012). Connexin and pannexin hemichannels in inflammatory responses of glia and neurons. Brain Res. 1487, 3-15. doi: 10.1016/j.brainres.2012.08.042

Berg, D. A., Belnoue, L., Song, H., and Simon, A. (2013). Neurotransmittermediated control of neurogenesis in the adult vertebrate brain. Development 140, 2548-2561. doi: 10.1242/dev.088005

Boassa, D., Qiu, F., Dahl, G., and Sosinsky, G. (2008). Trafficking dynamics of glycosylated pannexin 1 proteins. Cell Commun. Adhes. 15, 119-132. doi: 10.1080/15419060802013885

Bosher, S. K., and Warren, R. L. (1978). Very low calcium content of cochlear endolymph, an extracellular fluid. Nature 273, 377-378. doi: 10.1038/273 $377 \mathrm{a} 0$

Bruzzone, R., Barbe, M. T., Jakob, N. J., and Monyer, H. (2005). Pharmacological properties of homomeric and heteromeric pannexin hemichannels expressed in Xenopus oocytes. J. Neurochem. 92, 1033-1043. doi: 10.1111/j.14714159.2004.02947.x

Bruzzone, R., Hormuzdi, S. G., Barbe, M. T., Herb, A., and Monyer, H. (2003). Pannexins, a family of gap junction proteins expressed in brain. Proc. Natl. Acad. Sci. U.S.A. 100, 13644-13649. doi: 10.1073/pnas.22334 64100

Bukauskas, F. F., Kreuzberg, M. M., Rackauskas, M., Bukauskiene, A., Bennett, M. V., Verselis, V. K., et al. (2006). Properties of mouse connexin 30.2 and human connexin 31.9 hemichannels: implications for atrioventricular conduction in the heart. Proc. Natl. Acad. Sci. U.S.A. 103, 9726-9731. doi: 10.1073/pnas.0603372103

Burdakov, D., Luckman, S. M., and Verkhratsky, A. (2005). Glucose-sensing neurons of the hypothalamus. Philos. Trans. R. Soc. Lond. B Biol. Sci. 360, 2227-2235. doi: $10.1098 / \mathrm{rstb} .2005 .1763$

Chever, O., Lee, C. Y., and Rouach, N. (2014). Astroglial connexin43 hemichannels tune Basal excitatory synaptic transmission. J. Neurosci. 34, 11228-11232. doi: 10.1523/JNEUROSCI.0015-14.2014

Contreras, J. E., Sáez, J. C., Bukauskas, F. F., and Bennett, M. V. (2003). Gating and regulation of connexin 43 (Cx43) hemichannels. Proc. Natl. Acad. Sci. U.S.A. 100, 11388-11393. doi: 10.1073/pnas. 1434298100

Contreras, J. E., Sanchez, H. A., Veliz, L. P., Bukauskas, F. F., Bennett, M. V., and Sáez, J. C. (2004). Role of connexin-based gap junction channels and hemichannels in ischemia-induced cell death in nervous tissue. Brain Res. Brain Res. Rev. 47, 290-303. doi: 10.1016/j.brainresrev.2004. 08.002
Cotrina, M. L., Lin, J. H., Alves-Rodrigues, A., Liu, S., Li, J., Azmi-Ghadimi, H., et al. (1998). Connexins regulate calcium signaling by controlling ATP release. Proc. Natl. Acad. Sci. U.S.A. 95, 15735-15740. doi: 10.1073/pnas.95.26.15735

Dallerac, G., Chever, O., and Rouach, N. (2013). How do astrocytes shape synaptic transmission? Insights from electrophysiology. Front. Cell. Neurosci. 7:159. doi: 10.3389/fncel.2013.00159

Davalos, D., Grutzendler, J., Yang, G., Kim, J. V., Zuo, Y., Jung, S., et al. (2005). ATP mediates rapid microglial response to local brain injury in vivo. Nat. Neurosci. 8, 752-758. doi: $10.1038 / \mathrm{nn} 1472$

De Bock, M., Wang, N., Bol, M., Decrock, E., Ponsaerts, R., Bultynck, G., et al. (2012). Connexin 43 hemichannels contribute to cytoplasmic $\mathrm{Ca}^{2+}$ oscillations by providing a bimodal $\mathrm{Ca}^{2+}$-dependent $\mathrm{Ca}^{2+}$ entry pathway. J. Biol. Chem. 287, 12250-12266. doi: 10.1074/jbc.M111.299610

Dermietzel, R., Kremer, M., Paputsoglu, G., Stang, A., Skerrett, I. M., Gomes, D., et al. (2000). Molecular and functional diversity of neural connexins in the retina. J. Neurosci. 20, 8331-8343.

Dermietzel, R., and Spray, D. C. (1993). Gap junctions in the brain: where, what type, how many and why? Trends Neurosci. 16, 186-192. doi: 10.1016/01662236(93)90151-B

De Vuyst, E., Decrock, E., Cabooter, L., Dubyak, G. R., Naus, C. C., Evans, W. H., et al. (2006). Intracellular calcium changes trigger connexin 32 hemichannel opening. EMBO J. 25, 34-44. doi: 10.1038/sj.emboj.7600908

De Vuyst, E., Decrock, E., De Bock, M., Yamasaki, H., Naus, C. C., Evans, W. H., et al. (2007). Connexin hemichannels and gap junction channels are differentially influenced by lipopolysaccharide and basic fibroblast growth factor. Mol. Biol. Cell 18, 34-46. doi: 10.1091/mbc.E06-03-0182

De Vuyst, E., Wang, N., Decrock, E., De Bock, M., Vinken, M., Van Moorhem, M., et al. (2009). $\mathrm{Ca}^{(2+)}$ regulation of connexin 43 hemichannels in C6 glioma and glial cells. Cell Calcium 46, 176-187. doi: 10.1016/j.ceca.2009.07.002

D'hondt, C., Ponsaerts, R., De Smedt, H., Bultynck, G., and Himpens, B. (2009). Pannexins, distant relatives of the connexin family with specific cellular functions? Bioessays 31, 953-974. doi: 10.1002/bies.200800236

Dobrowolski, R., Sasse, P., Schrickel, J. W., Watkins, M., Kim, J. S., Rackauskas, M., et al. (2008). The conditional connexin43G138R mouse mutant represents a new model of hereditary oculodentodigital dysplasia in humans. Hum. Mol. Genet. 17, 539-554. doi: 10.1093/hmg/ddm329

Ebihara, L., Liu, X., and Pal, J. D. (2003). Effect of external magnesium and calcium on human connexin 46 hemichannels. Biophys. J. 84, 277-286. doi: 10.1016/S0006-3495(03)74848-6

Ebihara, L., and Steiner, E. (1993). Properties of a nonjunctional current expressed from a rat connexin 46 cDNA in Xenopus oocytes. J. Gen. Physiol. 102, 59-74. doi: 10.1085/jgp.102.1.59

Ebihara, L., Tong, J. J., Vertel, B., White, T. W., and Chen, T. L. (2011). Properties of connexin 46 hemichannels in dissociated lens fiber cells. Invest. Ophthalmol. Vis. Sci. 52, 882-889. doi: 10.1167/iovs.10-6200

Essenfelder, G. M., Bruzzone, R., Lamartine, J., Charollais, A., Blanchet-Bardon, C., Barbe, M. T., et al. (2004). Connexin30 mutations responsible for hidrotic ectodermal dysplasia cause abnormal hemichannel activity. Hum. Mol. Genet. 13, 1703-1714. doi: 10.1093/hmg/ddh191

Eugenin, E. A., Basilio, D., Sáez, J. C., Orellana, J. A., Raine, C. S., Bukauskas, F., et al. (2012). The role of gap junction channels during physiologic and pathologic conditions of the human central nervous system. J. Neuroimmune Pharmacol. 7, 499-518. doi: 10.1007/s11481-012-9352-5

Figiel, M., Allritz, C., Lehmann, C., and Engele, J. (2007). Gap junctional control of glial glutamate transporter expression. Mol. Cell. Neurosci. 35, 130-137. doi: 10.1016/j.mcn.2007.02.009

Giaume, C., Leybaert, L., Naus, C. C., and Sáez, J. C. (2013). Connexin and pannexin hemichannels in brain glial cells: properties, pharmacology, and roles. Front. Pharmacol. 4:88. doi: 10.3389/fphar.2013.00088

Gonzalez, D., Gomez-Hernandez, J. M., and Barrio, L. C. (2006). Species specificity of mammalian connexin-26 to form open voltage-gated hemichannels. FASEB J. 20, 2329-2338. doi: 10.1096/f.06-5828com

Grifa, A., Wagner, C. A., D'ambrosio, L., Melchionda, S., Bernardi, F., LopezBigas, N., et al. (1999). Mutations in GJB6 cause nonsyndromic autosomal dominant deafness at DFNA3 locus. Nat. Genet. 23, 16-18. doi: 10.1038/ 12612

Han, K. S., Woo, J., Park, H., Yoon, B. J., Choi, S., and Lee, C. J. (2013). Channel-mediated astrocytic glutamate release via Bestrophin-1 targets synaptic NMDARs. Mol. Brain 6:4. doi: 10.1186/1756-6606-6-4 
Han, Y., Yu, H. X., Sun, M. L., Wang, Y., Xi, W., and Yu, Y. Q. (2014). Astrocyterestricted disruption of connexin-43 impairs neuronal plasticity in mouse barrel cortex. Eur. J. Neurosci. 39, 35-45. doi: 10.1111/ejn.12394

Hansen, D. B., Braunstein, T. H., Nielsen, M. S., and Macaulay, N. (2014). Distinct permeation profiles of the connexin 30 and 43 hemichannels. FEBS Lett. 588, 1446-1457. doi: 10.1016/j.febslet.2014.01.036

Hofer, A., and Dermietzel, R. (1998). Visualization and functional blocking of gap junction hemichannels (connexons) with antibodies against external loop domains in astrocytes. Glia 24, 141-154.

Iglesias, R., Dahl, G., Qiu, F., Spray, D. C., and Scemes, E. (2009). Pannexin 1: the molecular substrate of astrocyte "hemichannels". J. Neurosci. 29, 7092-7097. doi: 10.1523/JNEUROSCI.6062-08.2009

Jourdain, P., Bergersen, L. H., Bhaukaurally, K., Bezzi, P., Santello, M., Domercq, M., et al. (2007). Glutamate exocytosis from astrocytes controls synaptic strength. Nat. Neurosci. 10, 331-339. doi: 10.1038/nn1849

Kamermans, M., and Fahrenfort, I. (2004). Ephaptic interactions within a chemical synapse: hemichannel-mediated ephaptic inhibition in the retina. Curr. Opin. Neurobiol. 14, 531-541. doi: 10.1016/j.conb.2004.08.016

Kang, J., Kang, N., Lovatt, D., Torres, A., Zhao, Z., Lin, J., et al. (2008). Connexin 43 hemichannels are permeable to ATP. J. Neurosci. 28, 4702-4711. doi: 10.1523/JNEUROSCI.5048-07.2008

Kawamura, M. Jr., Ruskin, D. N., and Masino, S. A. (2010). Metabolic autocrine regulation of neurons involves cooperation among pannexin hemichannels, adenosine receptors, and KATP channels. J. Neurosci. 30, 3886-3895. doi: 10.1523/JNEUROSCI.0055-10.2010

Kienitz, M. C., Bender, K., Dermietzel, R., Pott, L., and Zoidl, G. (2011). Pannexin 1 constitutes the large conductance cation channel of cardiac myocytes. J. Biol. Chem. 286, 290-298. doi: 10.1074/jbc.M110.163477

Kimelberg, H. K. (2004). Increased release of excitatory amino acids by the actions of ATP and peroxynitrite on volume-regulated anion channels (VRACs) in astrocytes. Neurochem. Int. 45, 511-519. doi: 10.1016/j.neuint.2003. 11.002

Klaassen, L. J., Sun, Z., Steijaert, M. N., Bolte, P., Fahrenfort, I., Sjoerdsma, T., et al. (2011). Synaptic transmission from horizontal cells to cones is impaired by loss of connexin hemichannels. PLoS Biol. 9:e1001107. doi: 10.1371/journal.pbio. 1001107

Lai, C. P., Bechberger, J. F., Thompson, R. J., Macvicar, B. A., Bruzzone, R., and Naus, C. C. (2007). Tumor-suppressive effects of pannexin 1 in C6 glioma cells. Cancer Res. 67, 1545-1554. doi: 10.1158/0008-5472.CAN-06-1396

Ledoux, J. (2007). The amygdala. Curr. Biol. 17, R868-R874. doi: 10.1016/j.cub.2007.08.005

Levin, B. E., Routh, V. H., Kang, L., Sanders, N. M., and Dunn-Meynell, A. A. (2004). Neuronal glucosensing: what do we know after 50 years? Diabetes 53, 2521-2528. doi: 10.2337/diabetes.53.10.2521

Leybaert, L., and Sanderson, M. J. (2012). Intercellular $\mathrm{Ca}^{(2+)}$ waves: mechanisms and function. Physiol. Rev. 92, 1359-1392. doi: 10.1152/physrev. 00029.2011

Li, H., Liu, T. F., Lazrak, A., Peracchia, C., Goldberg, G. S., Lampe, P. D., et al. (1996). Properties and regulation of gap junctional hemichannels in the plasma membranes of cultured cells. J. Cell Biol. 134, 1019-1030. doi: 10.1083/jcb.134.4.1019

Li, Y., Du, X. F., Liu, C. S., Wen, Z. L., and Du, J. L. (2012). Reciprocal regulation between resting microglial dynamics and neuronal activity in vivo. Dev. Cell 23, 1189-1202. doi: 10.1016/j.devcel.2012.10.027

Liebmann, M., Stahr, A., Guenther, M., Witte, O. W., and Frahm, C. (2013). Astrocytic $\mathrm{Cx} 43$ and $\mathrm{Cx} 30$ differentially modulate adult neurogenesis in mice. Neurosci. Lett. 545, 40-45. doi: 10.1016/j.neulet.2013.04.013

Locovei, S., Wang, J., and Dahl, G. (2006). Activation of pannexin 1 channels by ATP through P2Y receptors and by cytoplasmic calcium. FEBS Lett. 580, 239-244. doi: 10.1016/j.febslet.2005.12.004

Loewenstein, W. R. (1981). Junctional intercellular communication: the cell-to-cell membrane channel. Physiol. Rev. 61, 829-913.

Lutz, S. E., Zhao, Y., Gulinello, M., Lee, S. C., Raine, C. S., and Brosnan, C. F. (2009). Deletion of astrocyte connexins 43 and 30 leads to a dysmyelinating phenotype and hippocampal CAl vacuolation. J. Neurosci. 29, 7743-7752. doi: 10.1523/JNEUROSCI.0341-09.2009

Ma, W., Compan, V., Zheng, W., Martin, E., North, R. A., Verkhratsky, A., et al. (2012). Pannexin 1 forms an anion-selective channel. Pflugers Arch. 463, 585-592. doi: 10.1007/s00424-012-1077-z
Macvicar, B. A., and Thompson, R. J. (2010). Non-junction functions of pannexin-1 channels. Trends Neurosci. 33, 93-102. doi: 10.1016/j.tins.2009. 11.007

Makarenkova, H. P., and Shestopalov, V. I. (2014). The role of pannexin hemichannels in inflammation and regeneration. Front. Physiol. 5:63. doi: 10.3389/fphys.2014.00063

Massimini, M., and Amzica, F. (2001). Extracellular calcium fluctuations and intracellular potentials in the cortex during the slow sleep oscillation. J. Neurophysiol. 85, 1346-1350.

Moser, E. I., Krobert, K. A., Moser, M. B., and Morris, R. G. (1998). Impaired spatial learning after saturation of long-term potentiation. Science 281, 2038-2042. doi: 10.1126/science.281.5385.2038

Mylvaganam, S., Ramani, M., Krawczyk, M., and Carlen, P. L. (2014). Roles of gap junctions, connexins, and pannexins in epilepsy. Front. Physiol. 5:172. doi: 10.3389/fphys.2014.00172

Neary, J. T., and Zhu, Q. (1994). Signaling by ATP receptors in astrocytes. Neuroreport 5, 1617-1620. doi: 10.1097/00001756-19940815000019

Ngezahayo, A., Zeilinger, C., Todt, I., Marten, I., and Kolb, H. A. (1998). Inactivation of expressed and conducting $\mathrm{rCx} 46$ hemichannels by phosphorylation. Pflugers Arch. 436, 627-629. doi: 10.1007/s004240050681

Orellana, J. A., Avendano, B. C., and Montero, T. D. (2014). Role of connexins and pannexins in ischemic stroke. Curr. Med. Chem. 21, 2165-2182. doi: 10.2174/0929867321666131228191714

Orellana, J. A., Figueroa, X. F., Sanchez, H. A., Contreras-Duarte, S., Velarde, V., and Sáez, J. C. (2011a). Hemichannels in the neurovascular unit and white matter under normal and inflamed conditions. CNS Neurol. Disord. Drug Targets 10, 404-414. doi: 10.2174/187152711794653869

Orellana, J. A., Froger, N., Ezan, P., Jiang, J. X., Bennett, M. V., Naus, C. C., et al. (2011b). ATP and glutamate released via astroglial connexin 43 hemichannels mediate neuronal death through activation of pannexin 1 hemichannels. J. Neurochem. 118, 826-840. doi: 10.1111/j.1471-4159.2011.07210.x

Orellana, J. A., Giaume, C., and Sáez, J. C. (2011c). "Role of connexin hemichannels in neurodegeneration," in Neurodegenerative Diseases-Processes, Precvention, Protection and Monitoring, ed R. Chuen-Chung Chang (Rijeka: In Tech.), 235-254.

Orellana, J. A., Martinez, A. D., and Retamal, M. A. (2013). Gap junction channels and hemichannels in the CNS: regulation by signaling molecules. Neuropharmacology 75, 567-582. doi: 10.1016/j.neuropharm.2013.02.020

Orellana, J. A., Saez, P. J., Cortes-Campos, C., Elizondo, R. J., Shoji, K. F., ContrerasDuarte, S., et al. (2012a). Glucose increases intracellular free $\mathrm{Ca}^{(2+)}$ in tanycytes via ATP released through connexin 43 hemichannels. Glia 60, 53-68. doi: 10.1002/glia.21246

Orellana, J. A., Von Bernhardi, R., Giaume, C., and Sáez, J. C. (2012b). Glial hemichannels and their involvement in aging and neurodegenerative diseases. Rev. Neurosci. 23, 163-177. doi: 10.1515/revneuro-2011-0065

Ormel, L., and Gundersen, V. (2011). "Immunogold localization of connexin 43 in astrocytes: localization of hemichannels close to synapses," in IBRO 8th World Congress Abstract C049 (Florence).

Pannasch, U., Freche, D., Dallerac, G., Ghezali, G., Escartin, C., Ezan, P., et al. (2014). Connexin 30 sets synaptic strength by controlling astroglial synapse invasion. Nat. Neurosci. 17, 549-558. doi: 10.1038/nn.3662

Pannasch, U., and Rouach, N. (2013). Emerging role for astroglial networks in information processing: from synapse to behavior. Trends Neurosci. 36, 405-417. doi: 10.1016/j.tins.2013.04.004

Pannasch, U., Vargova, L., Reingruber, J., Ezan, P., Holcman, D., Giaume, C., et al. (2011). Astroglial networks scale synaptic activity and plasticity. Proc. Natl. Acad. Sci. U.S.A. 108, 8467-8472. doi: 10.1073/pnas.1016650108

Parpura, V., Scemes, E., and Spray, D. C. (2004). Mechanisms of glutamate release from astrocytes: gap junction "hemichannels", purinergic receptors and exocytotic release. Neurochem. Int. 45, 259-264. doi: 10.1016/j.neuint.2003.12.011

Pascual, O., Ben Achour, S., Rostaing, P., Triller, A., and Bessis, A. (2012). Microglia activation triggers astrocyte-mediated modulation of excitatory neurotransmission. Proc. Natl. Acad. Sci. U.S.A. 109, E197-205. doi: 10.1073/pnas.11110 98109

Paul, D. L., Ebihara, L., Takemoto, L. J., Swenson, K. I., and Goodenough, D. A. (1991). Connexin46, a novel lens gap junction protein, induces voltage-gated currents in nonjunctional plasma membrane of Xenopus oocytes. J. Cell Biol. 115, 1077-1089. doi: 10.1083/jcb.115.4.1077 
Pearson, R. A., Dale, N., Llaudet, E., and Mobbs, P. (2005). ATP released via gap junction hemichannels from the pigment epithelium regulates neural retinal progenitor proliferation. Neuron 46, 731-744. doi: 10.1016/j.neuron.2005.04.024

Pelligrino, D. A., Vetri, F., and Xu, H. L. (2011). Purinergic mechanisms in gliovascular coupling. Semin. Cell Dev. Biol. 22, 229-236. doi: 10.1016/j.semcdb.2011.02.010

Penuela, S., Bhalla, R., Gong, X. Q., Cowan, K. N., Celetti, S. J., Cowan, B. J., et al. (2007). Pannexin 1 and pannexin 3 are glycoproteins that exhibit many distinct characteristics from the connexin family of gap junction proteins. J. Cell Sci. 120, 3772-3783. doi: 10.1242/jcs.009514

Perea, G., Navarrete, M., and Araque, A. (2009). Tripartite synapses: astrocytes process and control synaptic information. Trends Neurosci. 32, 421-431. doi: 10.1016/j.tins.2009.05.001

Ponsaerts, R., De Vuyst, E., Retamal, M., D’hondt, C., Vermeire, D., Wang, N., et al. (2010). Intramolecular loop/tail interactions are essential for connexin 43-hemichannel activity. FASEB J. 24, 4378-4395. doi: 10.1096/fj.09153007

Prochnow, N., Abdulazim, A., Kurtenbach, S., Wildforster, V., Dvoriantchikova, G., Hanske, J., et al. (2012). Pannexin1 stabilizes synaptic plasticity and is needed for learning. PLoS ONE 7:e51767. doi: 10.1371/journal.pone.0051767

Quist, A. P., Rhee, S. K., Lin, H., and Lal, R. (2000). Physiological role of gapjunctional hemichannels. Extracellular calcium-dependent isosmotic volume regulation. J. Cell Biol. 148, 1063-1074. doi: 10.1083/jcb.148.5.1063

Ray, A., Zoidl, G., Weickert, S., Wahle, P., and Dermietzel, R. (2005). Site-specific and developmental expression of pannexin1 in the mouse nervous system. Eur. J. Neurosci. 21, 3277-3290. doi: 10.1111/j.1460-9568.2005.04139.x

Retamal, M. A., Froger, N., Palacios-Prado, N., Ezan, P., Saez, P. J., Sáez, J. C., et al. (2007). Cx43 hemichannels and gap junction channels in astrocytes are regulated oppositely by proinflammatory cytokines released from activated microglia. J. Neurosci. 27, 13781-13792. doi: 10.1523/JNEUROSCI.204207.2007

Riquelme, M. A., Kar, R., Gu, S., and Jiang, J. X. (2013). Antibodies targeting extracellular domain of connexins for studies of hemichannels. Neuropharmacology 75, 525-532. doi: 10.1016/j.neuropharm.2013.02.021

Rouach, N., Avignone, E., Meme, W., Koulakoff, A., Venance, L., Blomstrand, F., et al. (2002). Gap junctions and connexin expression in the normal and pathological central nervous system. Biol. Cell 94, 457-475. doi: 10.1016/S02484900(02)00016-3

Rouach, N., Koulakoff, A., Abudara, V., Willecke, K., and Giaume, C. (2008). Astroglial metabolic networks sustain hippocampal synaptic transmission. Science 322, 1551-1555. doi: 10.1126/science.1164022

Rozental, R., Giaume, C., and Spray, D. C. (2000). Gap junctions in the nervous system. Brain Res. Brain Res. Rev. 32, 11-15. doi: 10.1016/S0165-0173(99) 00095-8

Ryu, J. K., Choi, H. B., Hatori, K., Heisel, R. L., Pelech, S. L., McLarnon, J. G., et al. (2003). Adenosine triphosphate induces proliferation of human neural stem cells: role of calcium and p70 ribosomal protein S6 kinase. J. Neurosci. Res. 72, 352-362. doi: 10.1002/jnr.10507

Sáez, J. C., Berthoud, V. M., Branes, M. C., Martinez, A. D., and Beyer, E. C. (2003). Plasma membrane channels formed by connexins: their regulation and functions. Physiol. Rev. 83, 1359-1400.

Sáez, J. C., Retamal, M. A., Basilio, D., Bukauskas, F. F., and Bennett, M. V. (2005). Connexin-based gap junction hemichannels: gating mechanisms. Biochim. Biophys. Acta 1711, 215-224. doi: 10.1016/j.bbamem.2005.01.014

Sahu, G., Sukumaran, S., and Bera, A. K. (2014). Pannexins form gap junctions with electrophysiological and pharmacological properties distinct from connexins. Sci. Rep. 4:4955. doi: 10.1038/srep04955

Samoilova, M., Wentlandt, K., Adamchik, Y., Velumian, A. A., and Carlen, P. L. (2008). Connexin 43 mimetic peptides inhibit spontaneous epileptiform activity in organotypic hippocampal slice cultures. Exp. Neurol. 210, 762-775. doi: 10.1016/j.expneurol.2008.01.005

Schalper, K. A., Palacios-Prado, N., Orellana, J. A., and Sáez, J. C. (2008). Currently used methods for identification and characterization of hemichannels. Cell Commun. Adhes. 15, 207-218. doi: 10.1080/15419060802014198

Schulz, S. B., Klaft, Z. J., Rosler, A. R., Heinemann, U., and Gerevich, Z. (2012). Purinergic P2X, P2Y and adenosine receptors differentially modulate hippocampal gamma oscillations. Neuropharmacology 62, 914-924. doi: 10.1016/j.neuropharm.2011.09.024
Schutz, M., Scimemi, P., Majumder, P., De Siati, R. D., Crispino, G., Rodriguez, L., et al. (2010). The human deafness-associated connexin 30 T5M mutation causes mild hearing loss and reduces biochemical coupling among cochlear non-sensory cells in knock-in mice. Hum. Mol. Genet. 19, 4759-4773. doi: $10.1093 / \mathrm{hmg} / \mathrm{ddq} 402$

Shields, C. R., Klooster, J., Claassen, Y., Ul-Hussain, M., Zoidl, G., Dermietzel, R., et al. (2007). Retinal horizontal cell-specific promoter activity and protein expression of zebrafish connexin 52.6 and connexin 55.5. J. Comp. Neurol. 501, 765-779. doi: 10.1002/cne.21282

Shram, N. F., Netchiporouk, L. I., Martelet, C., Jaffrezic-Renault, N., and Cespuglio, R. (1997). Brain glucose: voltammetric determination in normal and hyperglycaemic rats using a glucose microsensor. Neuroreport 8, 1109-1112. doi: 10.1097/00001756-199703240-00009

Simard, M., Arcuino, G., Takano, T., Liu, Q. S., and Nedergaard, M. (2003). Signaling at the gliovascular interface. J. Neurosci. 23, 9254-9262.

Sosinsky, G. E., Boassa, D., Dermietzel, R., Duffy, H. S., Laird, D. W., Macvicar, B., et al. (2011). Pannexin channels are not gap junction hemichannels. Channels (Austin). 5, 193-197. doi: 10.4161/chan.5.3.15765

Spray, D. C., Duffy, H. S., and Scemes, E. (1999). Gap junctions in glia. Types, roles, and plasticity. Adv. Exp. Med. Biol. 468, 339-359. doi: 10.1007/978-14615-4685-6_27

Stehberg, J., Moraga-Amaro, R., Salazar, C., Becerra, A., Echeverria, C., Orellana, J. A., et al. (2012). Release of gliotransmitters through astroglial connexin 43 hemichannels is necessary for fear memory consolidation in the basolateral amygdala. FASEB J. 26, 3649-3657. doi: 10.1096/ff.11-198416

Suadicani, S. O., Brosnan, C. F., and Scemes, E. (2006). P2X7 receptors mediate ATP release and amplification of astrocytic intercellular $\mathrm{Ca}^{2+}$ signaling. J. Neurosci. 26, 1378-1385. doi: 10.1523/JNEUROSCI.3902-05.2006

Sun, Z., Risner, M. L., Van Asselt, J. B., Zhang, D. Q., Kamermans, M., and McMahon, D. G. (2012). Physiological and molecular characterization of connexin hemichannels in zebrafish retinal horizontal cells. J. Neurophysiol. 107, 2624-2632. doi: 10.1152/jn.01126.2011

Theis, M., Jauch, R., Zhuo, L., Speidel, D., Wallraff, A., Doring, B., et al. (2003). Accelerated hippocampal spreading depression and enhanced locomotory activity in mice with astrocyte-directed inactivation of connexin43. J. Neurosci. 23, 766-776.

Theis, M., Sohl, G., Eiberger, J., and Willecke, K. (2005). Emerging complexities in identity and function of glial connexins. Trends Neurosci. 28, 188-195. doi: 10.1016/j.tins.2005.02.006

Thompson, R. J., Jackson, M. F., Olah, M. E., Rungta, R. L., Hines, D. J., Beazely, M. A., et al. (2008). Activation of pannexin-1 hemichannels augments aberrant bursting in the hippocampus. Science 322, 1555-1559. doi: $10.1126 /$ science. 1165209

Thompson, R. J., and Macvicar, B. A. (2008). Connexin and pannexin hemichannels of neurons and astrocytes. Channels (Austin). 2, 81-86. doi: 10.4161/chan.2.2.6003

Torres, A., Wang, F., Xu, Q., Fujita, T., Dobrowolski, R., Willecke, K., et al. (2012). Extracellular $\mathrm{Ca}^{(2+)}$ acts as a mediator of communication from neurons to glia. Sci. Signal. 5, ra8. doi: 10.1126/scisignal.2002160

Valiunas, V., and Weingart, R. (2000). Electrical properties of gap junction hemichannels identified in transfected HeLa cells. Pflugers Arch. 440, 366-379. doi: $10.1007 /$ s004240000294

Velasquez, S., and Eugenin, E. A. (2014). Role of Pannexin-1 hemichannels and purinergic receptors in the pathogenesis of human diseases. Front. Physiol. 5:96. doi: 10.3389/fphys.2014.00096

Wallraff, A., Kohling, R., Heinemann, U., Theis, M., Willecke, K., and Steinhauser, C. (2006). The impact of astrocytic gap junctional coupling on potassium buffering in the hippocampus. J. Neurosci. 26, 5438-5447. doi 10.1523/JNEUROSCI.0037-06.2006

Wang, N., De Bock, M., Decrock, E., Bol, M., Gadicherla, A., Vinken, M., et al. (2013a). Paracrine signaling through plasma membrane hemichannels. Biochim. Biophys. Acta 1828, 35-50. doi: 10.1016/j.bbamem.2012.07.002

Wang, N., De Vuyst, E., Ponsaerts, R., Boengler, K., Palacios-Prado, N., Wauman, J., et al. (2013b). Selective inhibition of Cx43 hemichannels by Gap19 and its impact on myocardial ischemia/reperfusion injury. Basic Res. Cardiol. 108, 309. doi: 10.1007/s00395-012-0309-x

Wicki-Stordeur, L. E., Dzugalo, A. D., Swansburg, R. M., Suits, J. M., and Swayne, L. A. (2012). Pannexin 1 regulates postnatal neural stem and progenitor cell proliferation. Neural Dev. 7, 11. doi: 10.1186/1749-8104-7-11 
Wicki-Stordeur, L. E., and Swayne, L. A. (2013). Panxl regulates neural stem and progenitor cell behaviours associated with cytoskeletal dynamics and interacts with multiple cytoskeletal elements. Cell Commun. Signal. 11:62. doi: 10.1186/1478-811X-11-62

Willecke, K., Eiberger, J., Degen, J., Eckardt, D., Romualdi, A., Guldenagel, M., et al. (2002). Structural and functional diversity of connexin genes in the mouse and human genome. Biol. Chem. 383, 725-737. doi: 10.1515/BC.2002.076

Ye, Z. C., Wyeth, M. S., Baltan-Tekkok, S., and Ransom, B. R. (2003). Functional hemichannels in astrocytes: a novel mechanism of glutamate release. J. Neurosci. 23, 3588-3596.

Zimmermann, H. (2011). Purinergic signaling in neural development. Semin. Cell Dev. Biol. 22, 194-204. doi: 10.1016/j.semcdb.2011.02.007

Zoidl, G., Petrasch-Parwez, E., Ray, A., Meier, C., Bunse, S., Habbes, H. W., et al. (2007). Localization of the pannexin 1 protein at postsynaptic sites in the cerebral cortex and hippocampus. Neuroscience 146, 9-16. doi: 10.1016/j.neuroscience.2007.01.061
Conflict of Interest Statement: The authors declare that the research was conducted in the absence of any commercial or financial relationships that could be construed as a potential conflict of interest.

Received: 30 June 2014; accepted: 06 October 2014; published online: 04 November 2014.

Citation: Cheung G, Chever $O$ and Rouach $N$ (2014) Connexons and pannexons: newcomers in neurophysiology. Front. Cell. Neurosci. 8:348. doi: 10.3389/fncel. 2014.00348

This article was submitted to the journal Frontiers in Cellular Neuroscience.

Copyright (c) 2014 Cheung, Chever and Rouach. This is an open-access article distributed under the terms of the Creative Commons Attribution License (CC BY). The use, distribution or reproduction in other forums is permitted, provided the original author(s) or licensor are credited and that the original publication in this journal is cited, in accordance with accepted academic practice. No use, distribution or reproduction is permitted which does not comply with these terms. 